\title{
Evaluation of the treatment utility of the analog functional analysis and the structured descriptive assessment
}

Carie L. English

West Virginia University

Follow this and additional works at: https://researchrepository.wvu.edu/etd

\section{Recommended Citation}

English, Carie L., "Evaluation of the treatment utility of the analog functional analysis and the structured descriptive assessment" (2004). Graduate Theses, Dissertations, and Problem Reports. 2070.

https://researchrepository.wvu.edu/etd/2070

This Dissertation is protected by copyright and/or related rights. It has been brought to you by the The Research Repository @ WVU with permission from the rights-holder(s). You are free to use this Dissertation in any way that is permitted by the copyright and related rights legislation that applies to your use. For other uses you must obtain permission from the rights-holder(s) directly, unless additional rights are indicated by a Creative Commons license in the record and/ or on the work itself. This Dissertation has been accepted for inclusion in WVU Graduate Theses, Dissertations, and Problem Reports collection by an authorized administrator of The Research Repository @ WVU.

For more information, please contact researchrepository@mail.wvu.edu. 
Evaluation of the Treatment Utility of the Analog Functional Analysis and the Structured Descriptive Assessment

\author{
Carie L. English
}

Dissertation submitted to the College of Arts and Sciences at West Virginia University in partial fulfillment of the requirements

for the degree of

\author{
Doctor of Philosophy \\ in \\ Psychology
}

\author{
Cynthia M. Anderson, Ph.D., Committee Chair \\ Kennon A. Lattal, Ph.D. \\ Jennifer McFarland, Ph.D. \\ Tracy Morris, Ph.D. \\ Michael Perone, Ph.D. \\ Department of Psychology
}
Morgantown, West Virginia 2004

Keywords: functional assessment, treatment utility, problem behavior, analog functional analysis, structured descriptive assessment 


\section{Abstract \\ Evaluation of the Treatment Utility of the Analog Functional Analysis and the Structured Descriptive Assessment}

\section{Carie L. English}

The analog functional analysis exerts a great deal of control over environmental variables due to the systematic manipulation of specific antecedent and consequent events. Previous research suggests that the treatment utility of the analog might be enhanced by including environmental variables specific to the participant (e.g., caregivers). An alternative to this is to conduct the functional assessment in the natural environment. The structured descriptive assessment (SDA) involves systematic manipulation of antecedent events but is conducted by caregivers in individuals' natural environment. The purpose of this study was to examine the treatment utility of the analog functional analysis and the SDA by comparing results of the analog functional analysis when conducted by experimenters versus caregivers to results obtained from the SDA. Additionally, consequence-based interventions based on the results of each assessment were evaluated. Four participants with developmental disabilities and their caregivers participated. For all four participants, different patterns of responding were observed across all three assessments. For all participants, the interventions based on the results of the SDA were more effective than interventions based on the analog functional analysis. 
Table of Contents

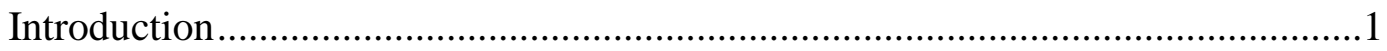

Experiment 1: Assessment ..............................................................................2

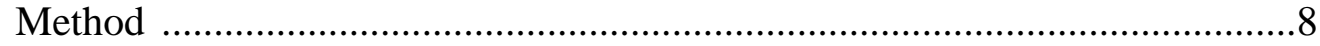

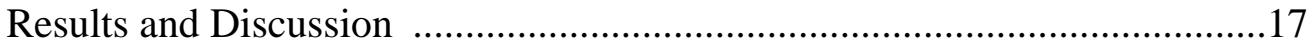

Experiment 1: Intervention ................................................................24

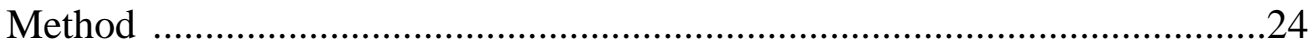

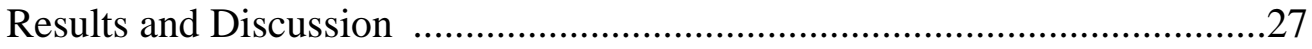

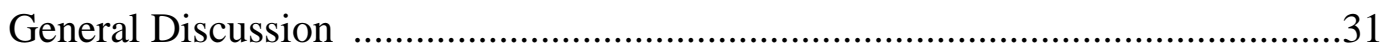

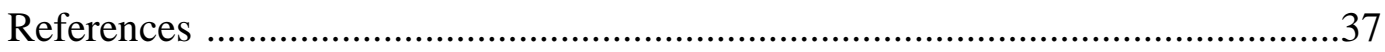

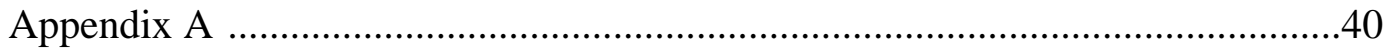

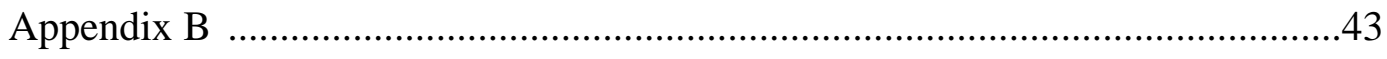

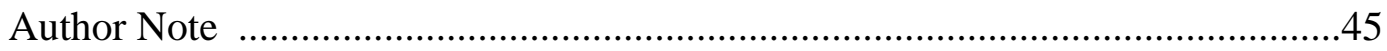

Table 1: Mean Agreement Scores in the Analog Functional Analysis ................ 46

Table 2: Mean Agreement Scores in the SDA ….............................................47

Table 3: Conditional Probability Formulas for the Analog Functional Analysis .48

Table 4: Therapist Responses in the Analog Functional Analysis .....................49

Table 5: Procedural Integrity Measures for the Analog Functional Analysis ......50

Table 6: Conditional Probability Formulas for the SDA …................................51

Table 7: Events Hypothesized to Precede and Maintain Problem Behavior ........52

Table 8: Mean Percentage of Intervals Containing Antecedent Events ................53

Table 9: Mean Agreement Scores During Intervention......................................54

Table 10: Procedural Integrity Measures During Intervention .............................55

Figure 1: Assessment Results for Andrew ...................................................58

Figure 2: Assessment Results for Connor.......................................................59 
Figure 3: Assessment Results for Jim.......................................................60

Figure 4: Assessment Results for Susie .....................................................661

Figure 5: Intervention Results for Andrew ................................................62

Figure 6-7: Intervention Results for Connor...............................................63

Figure 8: Intervention Results for Susie .................................................65 
Evaluation of the Treatment Utility of the Analog Functional Analysis and the Structured Descriptive Assessment

A formal approach to the analysis of the function of problem behavior is a relatively recent phenomenon (Iwata, Vollmer, \& Zarcone, 1990; Pelios, Morren, Tesch, \& Axelrod, 1999), but one that has changed the treatment of problem behavior. Functional assessment consists of gathering information pertaining to the target behavior and environmental events that affect and are affected by the occurrence of the behavior (Iwata et al., 1990). Numerous strategies for conducting a functional assessment have been developed in recent years, and although all are used to gather information about environment behavior relations, differences exist in the degree of control exerted over environmental events and the amount of information gathered about environmental events that may be associated with the target response. Methods of functional assessment include indirect, descriptive, and experimental methods. Each method has both advantages and limitations for use in various situations.

\section{Indirect Assessment}

The simplest method of gathering information pertaining to problem behavior does not involve firsthand collection of such information. Rather, information is gathered via a caregiver or, if possible, the individual engaging in the behavior. Examples of indirect functional assessments include interviews (e.g., Functional Assessment Interview; O’Neill, Horner, Albin, Storey, \& Sprague, 1989) and rating scales (e.g., Motivation Assessment Scale; Durand \& Crimmins, 1988). Using an indirect functional assessment, caregivers are asked to describe events that occurred in the past and to draw conclusions regarding the function of the behavior. Although indirect assessments are efficient in terms of staff time requirements (only one person is needed to administer the assessments) and time needed to administer the assessment, there are several limitations. First, information gathered via indirect assessments is not always objective. Caregivers may disagree on antecedent events related to a person's problem behavior or may provide inaccurate reports of consequences (Shores, Wehby, \& Jack, 1999); thus, inconclusive or incorrect hypotheses pertaining to the function of problem behavior might be obtained. In addition, only a small number of studies have directly evaluated the reliability of descriptive methods. The results of these studies are somewhat discrepant. Some studies support the reliability of descriptive methods (e.g., Horner, Day, \& Day, 1997), and other studies demonstrate low reliability (e.g., Iwata et al., 1990). Most often, indirect assessments are used in 
conjunction with other types of functional assessment and are viewed as a useful starting point in a comprehensive functional assessment (O’Neill et al., 1997).

\section{Descriptive Assessment}

Descriptive assessments involve direct observation of behavior and environmental events to develop hypotheses about functional relations and to assess the natural covariation between problem behavior and antecedent and consequent events (Iwata, Vollmer, Zarcone, \& Rodgers, 1993). Descriptive assessments usually are conducted in the setting in which problem behavior occurs. For example, the ABC functional assessment (Bijou, Peterson, \& Ault, 1968) allows for identification and measurement of the target behavior and antecedent and consequent events across settings and time. Typically, observers record events occurring before and after instances of problem behavior using interval or time-sampling recording procedures. Categories of antecedent and consequent events that are temporally associated with problem behavior are identified based on the observations.

Descriptive methods of functional assessment often are considered advantageous because they allow for identification of hypotheses about functional relations that occur naturally, which enhances the treatment utility of the functional assessment. In addition, naturally occurring schedules of reinforcement might be observed because environmental events are not manipulated in any way. Yet, because environmental events are not manipulated, functional relations cannot be verified in the ABC assessment (Iwata, et al., 1990). Although specific events may appear to reliably precede or follow problem behavior during the observation, such events may not be directly related to the problem behavior. For example, problem behavior following prompts might be immediately followed by escape. Shortly after the task has been withdrawn, the participant may be provided with attention. If the ABC assessment is used to identify only those events that are temporally contiguous with problem behavior, the attention delivery may not even be recorded. Further, without experimental manipulation, it is difficult to determine which consequence (escape or attention) actually maintains responding in this situation. A second limitation of descriptive assessments is that problem behavior may not be observed. This may occur, for example, if caregivers have restructured the environment such that antecedent variables that reliably evoke problem behavior rarely occur. In such a case, extensive observation may be necessary to develop hypotheses about functional relations. 
In an effort to improve descriptive assessment procedures, Anderson and colleagues (Anderson, English, \& Hedrick, in press; Anderson \& Long, 2002; Freeman, Anderson, \& Scotti, 2000) developed the structured descriptive assessment (SDA). The SDA involves systematic and repeated manipulations of antecedent events in an individual's natural environment. Caregivers conduct all sessions and are told to implement consequent events as they typically would. Antecedent events manipulated in the SDA include those demonstrated through previous research to frequently be related to problem behavior and include attention deprivation, presentation of requests, and removal of preferred items or activities. Conditions are conducted at times when such antecedent events are likely to occur naturally. For example, the attention condition might be conducted during times when a teacher is working with other children or planning lessons for the next day and thus not directly interacting with the child. Anderson and Long conducted the SDA with four children with developmental disabilities exhibiting problem behavior and compared the results to those obtained from an analog functional analysis (Iwata, Dorsey, Slifer, Bauman, \& Bowman, 1982/1994). Similar hypotheses about functional relations were developed for three of four participants. For the fourth participant, discrepant hypotheses about functional relations were developed and a subsequent analysis of intervention effects supported hypotheses derived from the SDA.

\section{Experimental Analysis}

An experimental functional assessment (i.e., functional analysis) requires control over environmental variables so that environment-behavior relations can be verified through direct manipulation and replication (Iwata et. al, 1990). Of experimental methods of functional assessment, the analog functional analysis (Iwata et al., 1982/1994) is used most often in research settings and, because of its precision and control over environmental variables, is considered one of the most effective methods for identifying environment-behavior relations (Lerman \& Iwata, 1993). The analog functional analysis involves systematically manipulating antecedent and consequent events presumed to be analogous to events occurring in the natural environment. Typically, sessions are conducted in a controlled setting, such as a research laboratory, and are conducted by trained experimenters allowing for greater control over environmental events. The following conditions typically are conducted: attention, demand, tangible, play, and alone. The purpose of the attention condition is to determine whether problem behavior is maintained by the delivery of attention from others. In this condition, the antecedent 
condition is attention deprivation, and the consequence for problem behavior is attention delivery. The purpose of the demand condition is to determine if problem behavior is maintained by escape from requests to complete a presumably unpleasant task. In the demand condition, the antecedent condition is the presentation of tasks, and contingent on problem behavior, a brief 20 s escape from the task is presented. The tangible condition is conducted to test the hypothesis that problem behavior is maintained by access to tangibles. The antecedent condition is the removal of a reportedly preferred item or activity, and the consequence for problem behavior is brief (e.g., 20 s) access to the item. The purpose of the play condition is to control for the presence of the experimenter, the presence of preferred tangibles, and the absence of demands. There are no programmed consequences for problem behavior in this condition, and attention is delivered on a fixed-time schedule (e.g., FT 20 s). The alone condition is conducted if sensory reinforcement is hypothesized to be a maintaining variable for problem behavior. There are no programmed consequences for problem behavior.

Many view the analog functional analysis to be "superior for identifying causal relations" (Lerman \& Iwata, p. 293); however, limitations do exist. One limitation is that, because the analog is conducted in a tightly controlled environment and requires trained staff to conduct the analysis, it is difficult to implement in settings other than a research setting. Further, the analog functional analysis may not identify the variables that maintain problem behavior in the natural environment (Anderson, Freeman, \& Scotti, 1999; Carr, Yarbrough, \& Langdon, 1997; Mace, Lalli, Pinter Lalli, \& Shea, 1993). For example, Carr et al. observed little or no problem behavior during analog functional analyses conducted with three participants. They then conducted observations in the natural environment and identified idiosyncratic stimuli (e.g., presence of puzzles) that seemed related to problem behavior. When these stimuli were included in the analog functional analysis, functional relations were identified for all participants.

\section{Evaluating the Treatment Utility of the Analog Functional Analysis}

The external validity of the analog functional analysis generally is presumed because it is thought to be analogous to the individual's natural environment (Iwata et al., 1990; Iwata et al., 1993; Lerman \& Iwata, 1993). Many researchers argue that the treatment utility of the analog is established by the numerous studies demonstrating effective treatments following an analog functional analysis (e.g., Iwata, Pace, Dorsey, et al., 1994; Lerman \& Iwata, 1993). Nonetheless, efficacious interventions, even if based on the results of a functional analysis, often demonstrate 
little about the treatment utility of the analog functional analysis for at least three reasons. First, when interventions involve an aversive consequence, response suppression is likely to occur even if the aversive stimulus is not related to the function of problem behavior (e.g., Fisher et al., 1993; Fisher, Piazza, Bowman, Hagopian, \& Langdon, 1994; Hagopian, Fisher, Sullivan, Acquisto, \& LeBlanc, 1998; Wacker et al., 1990). For example, Hagopian et al. evaluated the effects of a functionally-derived intervention, functional communication training (differential reinforcement for an alternative behavior in the same response class as the targeted problem behavior), with and without the use of punishment with 14 participants who exhibited problem behavior maintained by socially-mediated consequences. For 11 participants, the punishment procedure used (e.g., facial screen, brief physical restraint) was unrelated to the function of problem behavior. For the remaining three participants, time-out or contingent demands were used dependent upon the function of problem behavior (i.e., time-out was used for attention maintained behavior, contingent demands for escape-maintained behavior). Although interventions suppressed responding at least $90 \%$ for all participants, results obtained with 11 of the 13 participants do not support the treatment utility of the analog because components of the interventions used (i.e., the aversive consequence) were not derived from the hypotheses obtained from the analyses.

Second, interventions frequently are implemented in the same environment in which the analysis was conducted (e.g., clinic room by trained experimenters), and not in the individual's natural environment where problem behavior typically occurs (e.g., Fisher, O'Connor, Kurtz, DeLeon, \& Gotjen, 2000; Hagopian et al., 1998; Shirley, Iwata, Kahng, Mazaleski, \& Lerman, 1997). Hence, the effectiveness of the intervention in the individual's natural environment is unknown. Even though an intervention might reduce problem behavior in a clinic room, it necessarily does not reduce problem behavior in the natural environment. Variables related to problem behavior present in the natural environment may not have been present in the clinic room, and thus, the function of problem behavior in the clinic may not be the same as in the natural environment. Also, interventions implemented in the clinic setting may not be feasible in the natural environment due to rich schedules or other competing events occurring simultaneously (e.g., siblings who need attention, dinner to be cooked, a ringing phone). As a result, the intervention likely is not effective in the natural environment. 
Finally, because a restricted set of variables (e.g., brief negative attention, access to only one item) is manipulated in the analog functional analysis, environment-behavior relations involving other variables, such as positive attention or requests to complete a specific activity, may not be identified (Carr et al., 1997; Iwata et al., 1990; Mace et al., 1993). The findings of Carr et al. (described earlier) suggest that including stimuli present in the natural environment might enhance the treatment utility of the analog functional analysis. One alternative to conducting informal observations prior to implementing an analog functional analysis (as demonstrated by Carr et al.) is to include stimuli that likely are present across multiple settings (i.e., caregivers) in the analog.

Previous research (English \& Anderson, 2004; Ringdahl \& Sellers, 2000) tentatively suggests that hypotheses derived from a functional analysis may be affected by who conducts the analysis, which may affect treatment utility of the analysis. To illustrate, English and Anderson examined the inclusion of caregivers in analog functional analyses with four individuals with developmentally disabilities who exhibited problem behavior. A reversal design (ABA) was used to compare caregiver-conducted analogs to experimenter-conducted analogs. Results indicated different patterns of responding across therapists for three of four participants. For two participants, the caregiver-conducted analysis suggested multiple variables maintaining problem behavior, whereas the experimenter conducted analysis suggested only one variable maintaining problem behavior. For the third participant, even though increased responding was observed in the same conditions of the two analyses, response rates differed. Although different patterns of problem behavior were observed for three of four participants, because the analyses were conducted in a controlled setting, and because interventions based on the analyses were not conducted in the natural environment, the extent to which the findings of either analysis enhance treatment utility is unclear.

In an attempt to evaluate the treatment utility of the analog functional analysis, several studies have compared results obtained from an analog functional analysis to results obtained from a descriptive assessment (Anderson \& Long, 2002; Freeman, et al., 2000; Lerman \& Iwata, 1993; Mace \& Lalli, 1991; Sasso et al., 1992). Lerman and Iwata conducted descriptive assessments and analog analyses with six participants to determine the extent to which the two assessments would yield similar functional relations of problem behavior. Descriptive assessments consisted of observations in participants’ natural environments during 15-min 
sessions. Results from the descriptive assessment were compared to results from the analog functional analysis for each participant. For five of the six participants, results from the two assessments did not agree; the descriptive assessment for each participant suggested problem behavior was maintained by both social positive and social negative reinforcement, whereas the analog suggested only one maintaining variable (either social positive or social negative reinforcement). Although Lerman and Iwata concluded that the analog functional analysis was more useful for identifying functional relations, this conclusion may be premature because the treatment utility of the two assessments was not evaluated.

As described earlier, Anderson and Long (2002) also compared results of the analog functional analysis to results obtained from a descriptive assessment (the SDA). Although treatment evaluations indirectly supported the treatment utility of the SDA (and the analog for the two participants for whom agreement between assessments was observed), the treatment utility of the analog for the participant with whom different hypotheses were derived was not directly evaluated. This could have been accomplished by implementing an intervention based on the hypothesis derived from the analog (access to tangibles) in the natural environment (the utility of the analog was indirectly assessed as the intervention based on the hypothesis derived from the SDA resulted in total suppression of problem behavior).

\section{Statement of the Problem}

Given the results of previous research (Anderson \& Long, 2002; English \& Anderson, 2004; Lerman \& Iwata, 1993), it is clear that further research examining the treatment utility of methods of functional assessment is needed. Although the analog functional analysis is useful for identifying causal relations among environmental events, the extent to which the results of the analog enhance treatment utility is not certain. A growing body of research suggests that including idiosyncratic variables, such as caregivers, may result in different patterns of responding (English \& Anderson; Ringdahl \& Sellers, 2000; Sasso et al., 1992). It has not yet been determined if inclusion of caregivers or other idiosyncratic variables in the analog enhances the treatment utility of the assessment. Although descriptive methods of functional assessment may appear to be have more utility (because they are conducted in the natural environment), the treatment utility of these assessments is not well-documented (Lerman \& Iwata, 1993). The SDA may have greater utility than other methods because it is conducted in the natural environment and involves systematic manipulation of antecedent variables, but only two studies to date 
(Anderson et al., in press; Anderson \& Long, 2001) have evaluated the treatment utility of this assessment.

The purpose of this study was to further evaluate the treatment utility of the analog functional analysis and the SDA. First, a direct replication of English and Anderson (2004) was conducted to evaluate further the extent to which the inclusion of caregivers in the analog functional analysis affected response patterns in the analog. To evaluate the extent to which hypotheses derived from the two analogs enhanced utility, the results obtained from caregiverconducted and experimenter-conducted analogs were compared to results obtained from the SDA. Finally, the treatment utility of these three assessments was evaluated by implementing interventions based on the results of the assessments (a systematic replication of Anderson \& Long, 2002).

\section{Experiment 1: Assessment}

\section{Method}

\section{Participants and Setting}

Four children with developmental delays referred for assessment and treatment of problem behavior and their caregivers participated in the study. Andrew was a 2-year-old boy with global developmental delays. Andrew was able to verbally request for preferred items and could follow simple two-step commands. Connor was an 8-year-old boy diagnosed with autism, functioning in the normal to mildly mentally retarded range of intellectual functioning. Connor was verbally able to request wanted items and could follow multiple step commands. Several medications had been used in an attempt to manage Connor's behavior prior to the study, but his mother was unable to provide accurate information as to the types of medication used or the dosage prescribed. Further, reports from Connor's teachers suggested that his mother did not provide medications to Connor on a consistent basis. Connor was taking Risperdal (4 mg) when the study began but given his caregiver's inconsistent use of medications in the past, the extent to which he took this medication reliably across the study is unclear. Jim was a 6-year-old boy diagnosed with autism. Jim could verbally request items and could follow complex commands. Prior to participation in the study Jim was given $40 \mathrm{mg}$ of Strattera each day for two weeks. The medication was removed just prior to his participation in the study. Susie was a 9-year-old girl diagnosed with autism. Susie could verbally request wanted items and could follow complex commands. She was estimated to be in the average range of intellectual functioning. Caregivers 
in the study were the children's mothers (Andrew, Jim, Susie) or teacher (Connor), whom had known Connor for four years.

Analog functional analyses were conducted in the applied behavior analysis laboratory in the Department of Psychology at West Virginia University. The room was equipped with a twoway mirror and contained a table, chairs, and materials relevant to each condition. SDA sessions were conducted in participants' homes (Andrew, Jim, Susie) or classroom (Connor). All sessions were $10 \mathrm{~min}$ in length and were conducted for approximately 2-4 hours daily, three to five times per week.

\section{Response Definitions and Interobserver Agreement}

Data were collected on problem behavior including aggression, disruption, and self-injury (SIB). Aggression included: biting (Andrew, Connor, Susie), hitting, (Andrew, Connor, Jim, Susie), kicking (Connor, Susie), pinching (Andrew, Connor, Susie), and scratching (Andrew, Connor, Susie). Disruption included: throwing objects landing further than 1 ' from a person (Andrew, Connor, Jim, Susie), hitting objects (Susie), and knocking over items (Jim, Susie). SIB included: hand biting (Connor, Susie), hair pulling (Andrew), head banging (Andrew, Jim), and leg hitting (Connor). Data were collected on therapist (i.e., the person conducting the session) responding as well (see below for details).

Analog functional analysis. Observers collected data on response frequency of problem behavior (individually defined as above) and compliance, defined as the participant completing a task following a verbal or gestural prompt. Frequency data also were collected on the following therapist responses: (a) prompt, defined as a verbal, gestural, or physical request; (b) attention delivery, defined as 3-s to 5-s verbal statements or physical interaction that was not a prompt; (c) delivery of tangible items, defined as placing a preferred item within reach of the participant; (d) removal of tangible items, defined as removing a preferred item from the participant; and (e) escape, scored when the therapist removed demand materials following problem behavior.

Data were collected using continuous recording on a real-time data collection program on desktop and laptop computers during both in vivo and videotaped sessions. Prior to beginning data collection in the experiment, data collectors were trained with this type of data collection until agreement scores were $80 \%$ or higher on all target responses for three consecutive sessions. Two observers independently scored responses across at least $40 \%$ of the sessions for each phase. Agreement coefficients for frequency measures were calculated by dividing sessions into 
continuous 10-s intervals and comparing observers' records for each interval and then dividing the smaller number of responses recorded by the larger number of responses recorded. The proportions then were averaged across the session and multiplied by 100 to obtain an agreement coefficient. Mean interobserver agreement across participants was 95\% (range 72-100\%) for problem behavior, 97\% (range 72-100\%) for compliance, 97\% (range 81-100\%) for prompts, 96\% (range 78-100\%) for attention delivery, 95\% (range 79-100\%) for escape delivery, 98\% (range 73-100\%) for tangible delivery, 98\% (range 92-100\%) escape withdrawal, and 98\% (range 78-100\%) for tangible removal. (See Table 1 for agreement coefficients for each participant.)

Structured descriptive assessment. Response definitions for problem behavior were identical to those in the analog functional analysis, and a frequency measure was used to score responses. Data on all therapist responses were scored using partial-interval recording across continuous 5-s intervals. Target therapist responses included prompts, escape, attention delivery and deprivation, and tangible delivery and removal. Prompts were defined as an instruction to complete academic tasks and included physical prompts and ongoing instructional contexts such as circle time. Escape was scored when prompts were absent for one complete interval following the delivery of a prompt in the previous interval and the child had not complied with the task. Attention delivery was scored when the therapist interacted, either verbally or physically, with the participant in a non-instructional manner. This included reprimands, verbal statements directed to the participant (e.g., “you are great”), and physical interaction, such as a hug or pat on the back. Attention deprivation was scored when attention had been absent for one complete interval and continued to be scored until attention or a prompt was delivered. Tangible delivery was defined as allowing access to a preferred item (defined prior to commencement of the assessment) including giving the item to the participant, telling the participant he or she could have the item, or allowing the participant to independently obtain the item. The response definition for tangible removal was identical to the analog functional analysis.

Interobserver agreement for problem behavior was coded for a minimum of $38 \%$ of all sessions for all participants and was calculated as described above for the analog functional analysis. For partial interval measures, total agreement was calculated. Total agreement was calculated by dividing the number of intervals in which both observers agreed on the occurrence and nonoccurrence of the response and dividing by the total number of intervals. Mean 
interobserver total agreement across participants was 98\% (range 83-100 \%) for problem behavior, 97\% (range 76-99\%) for compliance, 98\% (range 75-100\%) for prompts, 99\% (range 90-100\%) for instructional contexts, 98\% (range 75-100\%) for escape delivery, 91\% (range 77$94 \%$ ) for attention delivery, 92\% (range 71-96\%) for attention deprivation, 99\% (range 85100\%) for tangible delivery, and 98\% (range 75-100\%) for tangible removal. (See Table 2 for agreement coefficients for each participant.)

\section{Integrity Measurement}

Analog functional analysis. The occurrence of specific stimuli at certain times is critical to a demonstration of functional control in the analog functional analysis, as causal relations can be identified only when pre-specified environmental variables reliably occur at specified times. For example, if responding is high in the attention condition, but low in other conditions, it is assumed that social-positive reinforcement maintains problem behavior. This assumption can be made because, in the attention condition, attention deprivation preceded problem behavior and attention delivery followed problem behavior. In addition, demands are not present and the presence of tangible items is controlled. To ensure that caregivers delivered appropriate antecedent and consequent stimuli in the analog functional analysis, conditional probabilities were calculated as suggested by English and Anderson (2004). Specifically, frequency data were coded for all responses in the analog functional analysis. For problem behavior, proportions were calculated for each occurrence of a problem behavior that occurred in the presence of prompts and tangible deprivation to control for the presence of putative establishing operations. For example, when calculating the proportion of tangible deliveries following problem behavior, instances of problem behavior that occurred while a child already was playing with a preferred item and continued to have access to the preferred item were not included in the calculation. Instead, tangible delivery was scored only when it occurred in the presence of the antecedent of tangible deprivation. For attention delivery, proportions were calculated for all child target behavior because therapists should respond to each instance of problem behavior emitted by the child during the attention condition.

Formulas used to calculate conditional probabilities are included in Table 3. With the exception of the first event, correctly delivered prompts, two formulas were calculated for each environmental event. The first formula was used to determine the proportion of environmental events correctly delivered within $10 \mathrm{~s}$ before or after the problem behavior (event-based 
formula). This formula answers the question, "of all the times an environmental event (e.g., attention delivery) occurred, what proportion followed (or preceded) problem behavior?” The second formula displays the proportion of child responses preceded or followed by the environmental event within $10 \mathrm{~s}$ (behavior-based formula) and answers the question, "of all the instances of problem behavior, what proportion were preceded or followed by an environmental event?” Using tangible delivery in the tangible condition as an example, the results of the first formula indicate the proportion of all instances of tangible delivery that followed problem behavior. If the tangible condition is conducted properly, the resulting coefficient should be close to $100 \%$, indicating that tangible delivery occurred only after occurrences of problem behavior. The second calculation determines the proportion of problem behavior that was followed by tangible delivery (same or subsequent interval); the resulting coefficient should be close to $100 \%$, demonstrating that all or almost all instances of problem behavior were followed by tangible delivery.

To facilitate analysis of conditional probabilities in the analog functional analysis, proportions obtained from each session conducted with a specific participant were averaged within conditions to obtain a mean proportion of occurrence for each environment-behavior relation. For example, the proportion of all problem behavior that occurred in tangible conditions conducted by Andrew's mother and were followed by tangible delivery was calculated. Conditional probabilities were calculated for caregiver-conducted and experimenter-conducted sessions, and proportions obtained with caregivers as therapists were compared to the proportions obtained when experimenters conducted sessions to evaluate procedural integrity. Table 4 depicts therapist responses measured to assess procedural integrity. Conditional probabilities were calculated for all events across all conditions (e.g., attention delivery following problem behavior was calculated in all conditions not just the attention sessions). As shown in Table 5, overall caregivers implemented the analog functional analysis with a high degree of integrity. Caregivers occasionally delivered attention in conjunction with escape or tangible delivery but the most typical error was a failure to deliver any consequent event following problem behavior. Additionally, caregivers occasionally delivered a consequent event for inappropriate behavior that was not targeted (e.g., making high pitched noises). Finally, caregivers frequently delivered the tangible item for longer than the $15-25 \mathrm{~s}$ time window used in the formula. 
Structured descriptive assessment. To evaluate the relation between environmental events and problem behavior, conditional probabilities were calculated for the SDA because the occurrence of antecedent and consequent events is not controlled for in the SDA as in the analog functional analysis. Conditional probabilities were calculated in a similar manner to the proportions calculated for the analog functional analysis; however, proportions for environmental events (see Table 6) were based on the interval in which the event was scored because a partial interval measure was used to record all events in the SDA. All probabilities were coded based on the first occurrence of child behavior in each interval (i.e., as if child behavior was coded using a partial-interval procedure). Thus, for behavior-based probabilities, the proportion of problem behavior that occurred in the same interval (but before the caregiver response), or within one consecutive interval of the relevant environmental event, was calculated by dividing the number of intervals containing problem behavior preceding the environmental event by one interval or less by the total number of intervals containing problem behavior. For environment-based probabilities, the proportion of environmental events that followed problem behavior and occurred within the same interval (but after the response), or in the next adjacent interval, was calculated by dividing the number of intervals containing problem behavior preceding the environmental event by one interval or less by the total number of intervals containing the environmental event. Proportions were calculated in the presence of relevant antecedent events, as in the analog functional analysis. For example, the percentage of attention following problem behavior that occurred in the presence of attention deprivation within the demand condition was calculated.

Experimental Design and Procedure

An interview was completed on the initial visit with the participant and his/her caregiver to operationally define problem behavior, to identify situations that often occasion problem behavior, and to identify preferred items for use in the analog functional analysis and the SDA. Following completion of the interview, the SDA was conducted for all participants except (due to a scheduling conflict the analog functional analysis was completed first). The SDA was conducted using a multielement design. Following completion of the SDA, the analog analyses were conducted. The analog functional analyses were conducted using a multielement design embedded in a reversal design. The order in which analog analyses were conducted was counterbalanced across participants. Hence, for Connor and Jim, Phase A was conducted by the 
experimenter and Phase B was conducted by the caregiver. For Andrew and Susie, caregivers conducted Phase A and the experimenter conducted Phase B. For both assessments, sessions were conducted until stability (using visual inspection) in responding was observed in all conditions. Items used in the assessments (e.g., task materials, tangible items) were held constant across assessments. For example, items used in the tangible conditions of the analog assessments and the SDA were identical.

Caregiver training. Prior to beginning an assessment (either the SDA or the analog functional analysis), written information was provided to caregivers regarding the purpose of the assessment and the conditions conducted (Appendix A and B). Training for the analog functional analysis also included observing videotaped role-plays of analog functional analyses in which trained graduate and undergraduate students portray therapists and children. After review of the videotape, caregivers rehearsed analog sessions with trained graduate students role playing the child and received feedback from the experimenter. Rehearsal and feedback were conducted until caregivers respond appropriately at least $90 \%$ of the time during rehearsal of each session. Once this criterion was met, caregivers began conducting the analog functional analysis.

Prior to conducting a session for either assessment, instructions for conducting the session were reviewed verbally with the caregiver. Additional feedback on caregiver responding occurred following each session conducted by caregivers throughout both assessments. In the analog functional analysis, caregivers received coaching (verbal prompts provided by the experimenter) during the session if the procedure was not properly followed three times in succession (e.g., during the tangible condition, the parent delivers attention following problem behavior). For Susie, this occurred during one time during the first demand session and a total of three times during the first two tangible sessions. For Andrew, verbal prompts were given to his mother one time during the first demand session. Finally, Connor's teacher was verbally prompted during the first three demand sessions, during the first attention session, and during five tangible sessions. In the SDA, prompts to re-establish antecedent conditions were given if the antecedent condition was not maintained during the session (see below for further details). Analog functional analysis. The analog functional analysis was based on procedures described by Iwata et al. (1982/1994). Conditions were conducted in a multielement design and condition order was randomly determined; however, the same condition was not run three times in succession. The following conditions were conducted for all participants: demand, attention, 
tangible, and play. The alone condition also was conducted for Andrew and Jim. During the demand condition, instructional tasks were presented to the participant by the therapist using a sequential three-step prompting sequence (verbal, gestural, and physical prompts). Compliance following a verbal or gestural prompt resulted in brief verbal praise (e.g., “Great job!). Any instances of problem behavior during task delivery were followed by a 20-s removal of prompts and task materials. No programmed consequences were delivered for problem behavior that occurred during the 20-s intertrial interval (ITI). The purpose of this condition was to test the hypothesis that problem behavior was maintained by escape from tasks.

During the attention condition toys were available to the participant. The therapist was in the room and engaged in an activity (e.g., reading a magazine). Verbal attention (e.g., “Don’t do that.”) was delivered contingent on each occurrence of problem behavior (fixed ratio (FR) 1 schedule). This condition was designed to test the hypothesis that problem behavior was maintained by access to attention.

Prior to the tangible condition, the participant was provided with access to a preferred object (e.g., a video, based on caregiver report and informal observation prior to conducting the analog analysis) for $2 \mathrm{~min}$. The tangible item was removed at the onset of the session. Instances of problem behavior resulted in delivery of the tangible item for 20 s. No programmed consequences were delivered during the 20-s interval during which the item was available. This condition was conducted to determine whether problem behavior was maintained by access to preferred activities or items.

The play condition was conducted as a control condition and was designed to serve as an “ideal situation" and to control for the presence of the therapist, the presence of preferred tangibles, and the absence of demands. In the play condition, the therapist was present in the room. The participant was provided with access to a variety of items, including stimuli used in the attention and tangible conditions. The therapist provided brief verbal attention (e.g., "You are doing a nice job playing.) on a FT 20-s schedule. If problem behavior occurred within 5 s of scheduled attention delivery, attention was withheld until five consecutive seconds without problem behavior had passed. There were no programmed consequences for problem behavior.

The alone condition was conducted with Andrew and Jim because their mothers indicated that SIB occurred "all the time”, including during attention and tangible delivery and deprivation and when asked to complete a task. The alone condition was conducted to determine if problem 
behavior was maintained by automatic reinforcement. The participant was placed in the room without any toys or a therapist. There were no programmed consequences for problem behavior.

Structured descriptive assessment. The SDA was conducted based on procedures described by Anderson and Long (2002). Conditions were conducted during times of the day when activities relevant to conditions in the SDA normally occurred (e.g., demand sessions occurred when the caregiver normally asked the child to complete a task such as "circle time” or deskwork). The following conditions were conducted: attention, demand, tangible, and play. The tangible condition was not conducted with Connor because it was not a relevant antecedent event in the classroom setting. More specifically, Connor's teacher reported that items were never returned to him once removed and that little problem behavior was observed when Connor could not have something he wanted. Importantly, tangible removal occasionally occurred in other conditions allowing for evaluation of the antecedent event. To ensure that relevant antecedent stimuli (e.g., presentation of requests) occurred throughout a session, caregivers were prompted to reestablish the antecedent stimulus if it had not occurred for 2 consecutive min in the absence of problem behavior. For example, in the attention condition, if the caregiver had interacted with the child for 2 consecutive min in the absence of problem behavior, she was asked to please return to what she were doing before she began interacting with the child (e.g., preparing the next activity).

The purpose of the attention condition was to establish the antecedent of attention deprivation. This condition was conducted during times when the caregiver did not normally interact with the child (e.g., while cooking dinner or working with another child). Prior to conducting attention sessions, the caregiver was asked to interact with the child in a noninstructional manner for at least 2 min. Preferred tangibles (items used in the tangible condition) were not present during this time. The caregiver was told, "During this role-play we would like to see how your child behaves when you are engaged in another activity and cannot directly attend to your child. If your child engages in problem behavior, please do what you would normally do; respond as if we were not here.” The caregiver also was asked to keep preferred items out of sight of the child and to refrain from placing demands on the child in the absence of problem behavior.

The purpose of the task condition was to establish the antecedent of task presentation and was conducted during times when the child normally was expected to complete tasks (e.g., doing 
a math worksheet). At the start of task sessions, caregivers were told, "In this role-play, we would like to learn how your child responds when asked to complete a task. Please attempt to have the child work on activities he or she normally should be doing and use whatever strategies you normally use to get your child to complete the task. If your child engages in problem behavior, please do what you would normally do in this situation." In addition, the caregiver was asked to keep preferred items out of sight of the child in the absence of problem behavior.

The tangible condition was designed to establish the antecedent of removal of preferred items or activities. This condition was conducted during times when access to preferred activities or items normally ends. Prior to the start of the condition, the child had been given access to the preferred item or activity for at least $2 \mathrm{~min}$. Upon initiation of a tangible session, caregivers were told, "In this role-play, we want to learn how your child responds when preferred activities end. When we tell you to begin, please remove the preferred item. You may interact with your child how you wish but refrain from engaging your child in work activities. If your child engages in problem behavior, please do what you would normally do in this situation.”

The play condition was designed to simulate an enriched environment. Preferred items were available and the caregiver was free to interact with the child as they wished. Prior to the role-play, caregivers were told, "In this role-play, we want to learn how your child responds when you are not making requests and preferred items and attention are available. Please play with your child as you normally do. If your child engages in problem behavior, please do what you would normally do in this situation.” If the caregiver did not interact with the child or did not allow access to preferred items, or if she placed demands on the child for 2 consecutive minutes in the absence of problem behavior, the caregiver was asked to re-implement the antecedent events.

\section{Results and Discussion}

For each participant, mean rates of problem behavior across conditions of the analog functional analyses and the SDA, along with results of the conditional probabilities from the SDA are depicted in Figures 1 through 4 . Table 5 depicts procedural integrity data for the analog functional analysis and Table 7 contains the antecedent and consequent events hypothesized by each assessment to evoke and maintain problem behavior. Table 8 presents the mean percentage of intervals containing antecedent events in the analog functional analysis and the SDA. 
Results obtained with Andrew during the analog functional analysis are depicted in the top panel of Figure 1. The caregiver-conducted analysis occurred first with Andrew and problem behavior occurred only infrequently across conditions. In the last four sessions of Phase A, problem behavior occurred most often in the tangible condition $(M=.53$ per min, range $0.3-0.9)$. When an experimenter served as therapist (Phase B), rates of problem behavior were highest in the demand condition ( $M=1.62$ per min) and little to no responding was observed in other conditions. When Andrew's caregiver resumed as therapist in Phase A', rates of problem behavior again were elevated in the tangible condition; however, rates were higher than in Phase A $(M=0.6$ per min; range $0-1.2)$. Rates of problem behavior in the demand condition were similar to those observed in the experimenter-conducted phase. Because Andrew occasionally engaged in problem behavior during demand sessions in Phase A, this differential response pattern likely is not due to contacting the escape contingency for the first time with the experimenter. One possible explanation for higher rates in Phase A' is that prior to the start of the session (Andrew and his caregiver were in the room with materials waiting for the session to begin) and intermittently during escape intervals of Phase A', Andrew was allowed access to the demand items and when his caregiver attempted to remove the items, Andrew engaged in problem behavior. This occurred during many escape intervals increasing the overall rate of problem behavior. If one examines only responding that occurred during prompting, Alex emitted an average of 0.58 responses per min in the task condition of Phase A'.

Results obtained with Andrew suggested different hypotheses about environment behavior relations depending on who conducted the analysis. See Table 7 for a summary of hypothesized functional relations. Results obtained with the experimenter suggest responding was evoked by task presentation and maintained by escape or avoidance of tasks. In the presence of the caregiver, responding was evoked by tangible removal and maintained by access to tangibles and possibly by escape or avoidance from tasks.

Results of the SDA for Andrew are depicted in the middle panel of Figure 1. Rates of problem behavior were highest in the tangible condition suggesting that removal of preferred items occasioned problem behavior. Responding also occurred in the task and attention conditions (although more variably), suggesting that responding might also evoked by attention deprivation and requests to complete tasks. However, merely examining rates of problem behavior in the SDA does not necessarily yield what events are maintaining problem behavior 
because consequences were not programmed. Thus, conditional probabilities must be analyzed. The behavior-based formula (bottom left panel) yields the proportion of intervals scored with problem behavior followed by an event. The event-based formula (bottom right panel) yields the proportion of intervals scored with an event that followed problem behavior. In other words, the behavior-based formula provides information about the putative schedule of reinforcement and the event-based formula provides information about the proportion of environmental events that were delivered within $5 \mathrm{~s}$ of problem behavior. When examining the graphs, the antecedent event that occurred in each condition of the assessment (e.g., attention, demand) is depicted in parentheses, and the consequent event (e.g., attention delivery, escape) is listed under the antecedent event. Thus, the graphs represent the results of the behavior-based and environmentbased formulas for problem behavior that occurred in the presence of the putative establishing operation (e.g., attention deprivation) that occurred during each assessment condition.

The bottom panels depict the results of the conditional probabilities from the SDA. For Andrew, the bottom left panel (behavior-based graph) illustrates that when tangible deprivation occurred in any condition, attention followed at least 50\% of all problem behavior in the demand and play conditions and at least 95\% of problem behavior exhibited in the attention and tangible conditions. Tangible delivery never followed problem behavior in any condition. The bottom right panel (event-based graph) illustrates that in the presence of tangible deprivation in both the attention and tangible conditions, attention occurred most often following problem behavior. In the attention condition, $72 \%$ of intervals scored with attention (in the presence of tangible deprivation) followed problem behavior, and 76\% of intervals scored with attention followed problem behavior in the tangible condition. Taken together results of the SDA suggest that removal of preferred items evoked problem behavior and attention delivery maintained problem behavior.

Results of the assessments are summarized in Table 7. Results of the SDA were most consistent with the caregiver-conducted phases of the analog functional analysis which also suggested that removal of a preferred item occasioned problem behavior. However, the consequent event differed between the two assessments. The caregiver-conducted phases of the analog functional analysis suggested that access to the preferred item maintained problem behavior whereas the SDA suggested that access to attention maintained delivery. In the SDA, tangible delivery never followed problem behavior. Although attempts are made to minimize 
attention delivery in the tangible condition of the analog (for example, the therapist does not speak to the participant), tangible delivery is confounded with attention delivery as the therapist (caregiver in this case) delivers the item to the participant. Thus, it is possible that the reinforcer in the tangible condition of the caregiver phase of the analog analysis was attention; however results such as those obtained with Andrew typically are considered to suggest tangible reinforcement. Both the SDA and caregiver-conducted phases differed from the experimenterconducted phase of the analog which suggested that requests to complete a task and escape from those tasks occasioned and maintained problem behavior (see Table 7).

As shown in Table 8, antecedent events occurred with similar frequency to occurrences in the analog functional analysis with the exception of attention delivery during most conditions (except the attention condition). Specifically, more attention was delivered during tangible sessions of the SDA because Andrew's caregiver verbally responded to 95\% of problem behavior emitted by Andrew. In the analog, no attention should follow problem behavior during tangible sessions. Additionally, Andrew's caregiver provided attention more frequently throughout all conditions of the SDA, thus intervals scored with attention deprivation are lower overall throughout the SDA. The fact that intervals scored with relevant antecedent events (e.g., attention deprivation in the attention condition, prompts in the demand condition) in the SDA were similar to intervals scored with those antecedents in the analog provides evidence that the SDA was implemented accurately.

Procedural integrity data obtained in the analog functional analysis with Andrew are in Table 5. Andrew's caregiver implemented the antecedent and consequent events in the analog functional analysis with a high degree of accuracy. Proportions obtained with Andrew's caregiver ranged from 83-100\%, and proportions obtained with experimenters ranged from 99$100 \%$.

Connor

Results obtained with Connor are depicted in Figure 2. The experimenter-conducted analog functional analysis was conducted first with Connor. During the first experimenterconducted phase (Phase A), rates of problem behavior were highest during the demand $(M=5.55$ per min in the last four sessions) and tangible ( $M=1.75$ per min in the last four sessions) conditions. When Connor's caregiver served as therapist in phase B, problem behavior was elevated in all conditions except the play condition. During Phase A' when the experimenter 
again conducted the sessions, problem behavior again was observed primarily in the demand and tangible conditions. Taken together, results obtained with Connor suggested that problem behavior was maintained by access to preferred items and escape from demands when the experimenter conducted the sessions. When the caregiver conducted the sessions, access to preferred items and attention as well as escape from demands seemed to be maintaining problem behavior.

In the middle panel of Figure 2 are results from Connor's SDA. Problem behavior occurred most often during the demand condition. Results from the conditional probabilities are depicted in the lower panels of Figure 2. The behavior-based graph (lower left) demonstrates that in the task condition, problem behavior that occurred in the presence of requests to complete a task was followed by attention $70 \%$ of the time. Prompts were delivered during $3 \%$ of intervals in the attention condition and in these instances problem behavior was always followed by attention. The lower right graph, the event-based graph, demonstrates that in the presence of prompts, $50 \%$ of the attention delivered in the attention condition (interpret with caution as prompts occurred in only $3 \%$ of intervals) and $42 \%$ of the attention delivered in the demand condition occurred following problem behavior. Taken together, these results suggest that problem behavior following presentation of a prompt was likely to be followed by attention delivery; escape rarely followed problem behavior and, in fact (bottom right panel) was more likely to occur at other times than to follow problem behavior.

Results of the SDA were consistent with all phases of the analog functional analysis in suggesting that problem behavior was occasioned by requests to complete a task. However, the analog suggested that escape from tasks maintained problem behavior, whereas the SDA suggested attention maintained problem behavior. Additionally, the analog and SDA differed in that (a) both analogs suggested tangible removal to evoke and tangible delivery to maintain problem behavior, and (b) the caregiver-conducted analog suggested that attention deprivation evoked and access to attention maintained problem behavior (see Table 7).

Data presented in Table 8 suggest that with the exception of attention deprivation in the demand condition, antecedent events occurred at similar rates in the SDA and the analog functional analysis. Differences in levels of attention deprivation in demand sessions likely occurred because Connor's caregiver provided Connor with attention during escape intervals in the SDA but did not do so during the analog. 
Procedural integrity data from the analog are in Table 5. Connor's caregiver implemented the antecedent and consequent events with acceptable accuracy (range 76-98\%). Procedural integrity data were lowest for tangible removal because Connor's caregiver often allowed access to items for more than 15-25 s (the time window on which the formulas were based). Jim

Figure 3 displays results obtained with Jim. Phase A of the analog functional analysis (top panel) was conducted by the experimenter. Rates of problem behavior were highest in the demand and tangible conditions. Problem behavior was emitted an average of 1.5 times per minute in the demand condition and an average of 0.64 times per minute in the tangible condition. Responding gradually increased in the tangible condition and the mean of the final four sessions was 1.2 per min. In Phase B (caregiver-conducted), problem behavior occurred an average of 5.1 times per min during the tangible condition (removing session 57, during which abnormally high response rates were observed, results in a mean of 3.9 responses per min) and 2.4 times per min during the alone condition. When experimenters again conducted sessions, rates of problem behavior were highest in the demand and tangible conditions. Across phases, results of the analog functional analysis suggest that tangible removal evoked and access to preferred items maintained problem behavior. Additionally, when the experimenter conducted the analysis, task presentation evoked problem behavior and escape from requests to complete a task maintained problem behavior (see Table 7).

Results from the SDA are depicted in the middle panel of Figure 3. Little to no problem behavior occurred during the SDA. Jim's mother reported that, shortly after completing the analog functional analyses (but prior to conducting the SDA), Jim had ceased to exhibit problem behavior at home. Two possible explanations for this finding exist. One possibility is that Jim’s problem behavior was affected by medication dose. Prior to conducting the study Jim had been taking two medications (Risperdal and Strattera) which were removed when Jim began the study. A second possible explanation is that after participating in the analog functional analysis (which was conducted first due to schedule conflicts), Jim's mother may have changed the way she responded to Jim's problem behavior, resulting in a decrease in problem behavior at home. Anecdotally, Jim's mother reported that participation in the analog showed her that allowing Jim to have access to preferred items when he exhibited problem behavior was counterproductive. 
While conducting the SDA however, she reported that she responded to problem behavior as she always had.

Results of the conditional probabilities are depicted in the lower panels of Figure 3. Results should be interpreted with caution due to the fact that only 3 instances of problem behavior (occurring during session 2 and 5) were observed in the SDA. Problem behavior occurred after a preferred item was removed and was always followed by attention. The eventbased graph (lower right) reveals that attention was more likely to occur in the absence of problem behavior (25\% followed problem behavior).

Data presented in Table 8 suggest that overall antecedent events occurred at similar rates in the SDA and the analog functional analysis. Thus, the absence of problem behavior in the SDA cannot be attributed to the nonoccurrence of antecedent stimuli present in the analog. Jim's caregiver delivered more attention during the demand, play, and tangible sessions of the SDA. Additionally, prompts were delivered more often during demand sessions of the SDA. Fewer prompts were delivered during the experimenter analog because Jim engaged in problem behavior resulting in escape delivery.

Procedural integrity data obtained in the analysis with Jim are in Table 5. Jim’s caregiver implemented the antecedent and consequent events in the analog functional analysis with a high degree of accuracy (range 83-100\%).

Susie

Results obtained with Susie are displayed in Figure 4. Susie emitted problem behavior almost exclusively during the tangible conditions of caregiver conducted phases (A and A') and problem behavior rarely occurred during Phase B, the experimenter-conducted phase. Thus, the analog functional analysis suggested that, in the presence of Sarah’s caregiver, removal of preferred items evoked problem behavior and that problem behavior was maintained by access to preferred items.

The middle panel of Figure 4 depicts results from the SDA. As in the caregiverconducted analog functional analysis, problem behavior occurred most often during the tangible condition although problem behavior occasionally was observed in the demand condition. The lower panels depict conditional probability calculations. The behavior-based graph (lower left) demonstrates that, in the presence of tangible deprivation, tangible delivery followed problem behavior only infrequently, but most intervals scored with problem behavior were followed by 
attention delivery (43\% in the demand condition; $72 \%$ in the tangible condition). The lower right panel (event-based) demonstrates that the tangible item was more likely to be returned noncontingent on problem behavior in the tangible condition and that $67 \%$ of attention deliveries in the tangible condition followed problem behavior occurring in the presence of tangible deprivation. Only 28\% of all attention delivered in the demand condition in the presence of tangible deprivation occurred following problem behavior (tangible deprivation occurred in only $10 \%$ of intervals in the demand condition). Taken together, results of the SDA are similar to the results of the caregiver-conducted analog in suggesting that removal of preferred items occasioned problem behavior. The SDA, however, suggests that in the presence of tangible deprivation problem behavior was maintained by attention. In contrast, the caregiver-conducted analog suggests that access to the preferred item maintained problem behavior (see Table 7).

Data presented in Table 8 suggest that with the exception of attention deprivation in the tangible condition, most antecedent events occurred at similar rates in the SDA and the analog functional analysis. More attention was delivered during tangible sessions in the SDA because Susie’s caregiver delivered attention contingent on problem behavior.

Procedural integrity data obtained in the analysis with Susie are in Table 5. Susie’s caregiver conducted the analog functional analysis with a high degree of accuracy (range 84$100 \%)$.

\section{Experiment 2: Intervention}

The purpose of this experiment was to evaluate interventions based on the results of each assessment conducted in Experiment 1. Interventions were matched to the function of problem behavior as suggested by the assessments (see Table 7). As the purpose of this experiment was to evaluate the treatment utility of functional assessment methods, interventions to be evaluated involved only contingency manipulations and were single component interventions. After completion of the study, multi-component (e.g., antecedent manipulations, skills training, consequence manipulations) interventions were developed for all participants.

\section{Method}

\section{Participants and Setting}

Participants were the same as in Experiment 1 with the exception of Connor's teacher. Intervention for Connor was conducted over the summer with a different teacher. Baseline sessions were conducted prior to implementing interventions to ensure that similar rates of 
problem behavior occurred with the summer teacher. When school began again in the fall, baseline sessions again were conducted with his regular teacher before implementing an intervention. All interventions were implemented in the setting in which the SDA in Experiment 1 was conducted (i.e., school or home). Most sessions were $10 \mathrm{~min}$ long (see below) and were conducted one to three times a day, two to five times a week. All conditions were conducted until stability, via visual inspection, was obtained; however, a minimum of three sessions were conducted within each phase. An intervention was considered successful if it resulted in $80 \%$ or greater reduction in problem behavior relative to baseline.

\section{Response Definitions and Interobserver Agreement}

Response definitions for problem behavior were identical to those in Experiment 1. Observers used frequency measures to collect data on problem behavior and therapist responses. Therapist responses for attention delivery, attention deprivation, prompt delivery, escape, tangible delivery, and tangible removal were the same as in Experiment 1. One new therapist response was added, physical prompt contingent on problem behavior (Connor). Data collection and observer training were identical to Experiment 1. Interobserver agreement was collected on at least 38\% of all sessions. Agreement coefficients were calculated similarly to the SDA as in Experiment 1. Mean interobserver agreement across participants was 99\% (range 92-100\%) for problem behavior, 97\% (range 86-100\%) for compliance, 97\% (range 78-100\%) for prompts, 99\% (range 90-100\%) for instructional context, 98\% (range 93-100\%) for escape delivery, 93\% (range 81-100\%) for attention delivery, 98\% (range 92-100\%) for attention deprivation, 100\% for tangible delivery, and 98\% (range 95-100\%0 for tangible removal. (See Table 9 for agreement coefficients for each participant.)

\section{Integrity Measurement}

To ensure the intervention was implemented correctly, data were collected on the extent to which caregivers delivered relevant antecedent and consequent stimuli. Consequently, if interventions did not result in reductions in problem behavior, improper implementation could be ruled out as a reason. Conditional probabilities were calculated as for the SDA in Experiment 1. Only the antecedent and consequent events relevant to the baseline and intervention sessions (dependent upon the function of problem behavior) were evaluated. Overall, caregivers implemented all interventions with good procedural integrity (at lest 80\% accuracy; see Table 10 for the mean integrity coefficients for each participant). Caregivers tended to implement an 
incorrect consequent event in the initial sessions of each treatment (e.g., attention delivery rather than or in conjunction with a physical prompt). Over time fewer mistakes were made.

Procedure

For each participant, interventions were matched to the function of problem behavior as identified in the analog functional analysis and the SDA. A reversal design was used with Andrew (ABAB) and Connor (ABACAB). A multielement design was used with Susie. All sessions were conducted during times when results of a functional assessment (e.g., caregiver or experimenter-conducted analog, SDA) suggested problem behavior was likely to occur. Baseline sessions were conducted as described for the SDA in Experiment 1.

\section{Andrew}

For Andrew, baseline sessions were conducted during demand sessions (based on results from the experimenter analog) and during tangible sessions (based on results obtained in the caregiver analog and SDA). Little to no problem behavior was observed during demand baseline sessions, thus an intervention was not evaluated. Two interventions were evaluated during tangible sessions. One intervention (based on the caregiver analog suggesting access to tangibles to be the reinforcer) involved removing the preferred item at the start of the session and keeping it in "time out" contingent on problem behavior (in other words, the item was not returned to Andrew). Andrew's mother was told she could respond to problem behavior as she chose to as long as she did not return the preferred item. The second intervention (based on the SDA which suggested that problem behavior was evoked by tangible removal but maintained by attention) was similar to the first except that attention was withheld following the occurrence of problem behavior. Thus, attention delivery and tangible access never followed problem behavior during this intervention.

\section{Connor}

For Connor, baseline sessions were conducted during attention sessions (based on the caregiver analog), demand sessions (based on the caregiver and experimenter analogs and SDA), and during tangible sessions (based on caregiver and experimenter analogs). Little to no problem behavior was observed during baseline attention and tangible sessions; thus, interventions were not evaluated. Two interventions were evaluated during demand sessions. One intervention (based on both analogs which suggested that problem behavior occurring in the presence of prompts was maintained by escape from prompts) consisted of a sequential three prompt 
sequence (as described in Experiment 1) with a 15-s break contingent on compliance. No attention was delivered during the break interval. Contingent on problem behavior, Connor's teacher physically prompted Connor to complete the task. The second intervention (based on results of the SDA which suggested that problem behavior in the presence of tasks was maintained by attention) was the same as the above intervention with the inclusion of noncontingent attention delivery during the entire $15 \mathrm{~s}$ break. Because the delivery of a $15 \mathrm{~s}$ break abolished the hypothesized establishing operation (prompts), 15 s were added to the session each time a break was delivered.

\section{Jim}

Baseline sessions were conducted during demand sessions (based on the experimenter analog) and tangible sessions (based on the experimenter and caregiver analogs). No problem behavior was observed during the SDA. Little to no problem behavior was observed during any of the baseline sessions so no intervention was evaluated.

\section{Susie}

Baseline sessions were conducted during tangible sessions based on the results of the caregiver analog and the SDA. Two interventions were evaluated. One intervention (based on the caregiver analog which suggested problem behavior was maintained by tangible delivery) included not allowing Susie access to the television program she preferred to watch. Susie’s mother was told she could respond to problem behavior as she wished as long as she did not allow Susie access to the television. The second intervention (based on the SDA which suggested that problem behavior occurring following tangible removed was maintained by attention and, intermittently, by access to the preferred item) was similar to the first except that problem behavior was placed on extinction; thus, attention delivery occurred only for appropriate behavior.

\section{Results and Discussion}

\section{Andrew}

Treatment results for demand sessions for Andrew are depicted in the top panel of Figure 5. Andrew rarely emitted problem behavior during baseline so treatment for escape maintained responding was not evaluated. In baseline during tangible sessions (middle panel), Andrew emitted an average of 1.4 problem behaviors per min. The intervention based on the results of the caregiver-conducted analog (toy removed) did not result in significant decreases in behavior. 
Following removal of the preferred toy, attention was delivered following nearly every instance of problem behavior either as negative attention or as a means of redirecting Andrew to interact with another toy. The intervention based on the results of the SDA (toy removed plus attention delivery for appropriate behavior only) decreased rates of problem behavior to zero. Following a reversal to baseline to evaluate functional control, rates of problem behavior again decreased to zero. Taken together, the results obtained with Andrew suggest that the SDA had the greatest treatment utility. Interventions based on the results of the experimenter-conducted analog were not needed as little to no problem behavior occurred in demand situations occurring at home in the presence of his mother.

Conditional probabilities are depicted in the bottom panel of Figure 5. Results show that problem behavior occurred during demand sessions was followed by attention $25 \%$ of the time but this only accounted for $2 \%$ of the attention Andrew received during demand sessions. Thus, it is not likely that attention was maintaining problem behavior occurring in the presence of prompts. Results from the frequency graph support this. During tangible sessions, attention continued to follow most instances of problem behavior (at least 95\%) occurring during tangible deprivation during baseline sessions and the intervention consisting of toy removal only. Attention followed only $8 \%$ of problem behavior occurring during tangible deprivation when the caregiver implemented toy removal plus attention extinction, and the tangible was never returned contingent on problem behavior during either intervention, suggesting the interventions were implemented accurately.

Procedural integrity data for both treatments are shown in Table 10. The coefficients shown reveal the accuracy with which caregivers implemented the appropriate consequent events. For example, attention delivery should not have occurred following problem behavior during the toy removal plus attention extinction intervention. Andrew's mother delivered $99 \%$ of attention at appropriate times (in the absence of problem behavior); thus, only $1 \%$ of the attention delivered followed problem behavior. Overall, Andrew's caregiver implemented the intervention with greater than $90 \%$ accuracy. Most errors (i.e., attention delivery following problem behavior) occurred in initial treatment sessions and immediately following reversal back to the treatment.

Connor 
Treatment results for Connor are depicted in Figure 6 and 7. Figure 6 depicts rates of problem behavior during attention (top panel) and tangible (bottom panel) sessions. Connor emitted low rates of problem behavior during both attention and tangible sessions and consequently, an intervention based on the hypotheses that access to attention and access to tangibles maintained problem behavior were not implemented.

The top panel of Figure 7 depicts rates of problem behavior in demand baseline and intervention sessions. During baseline, Connor emitted an average of 2.0 problem behaviors per min in the last 11 sessions. The first intervention implemented (based on the results of the SDA) included physical guidance plus a 15-s break during which Connor's teacher provided attention. After an initial increase in responding relative to baseline, a gradual suppression in problem behavior was observed and average responding in the final six sessions was 69\% below baseline rates. Following a return to baseline during which rates of problem behavior again increased, the second intervention (based on the results of the analog) was implemented. The intervention consisted of physical guidance plus a 15-s break but did not include attention during the break. This intervention had little to no effect on problem behavior. After a brief return to baseline the intervention was re-implemented. Thus, results suggest that the treatment based on the SDA was most efficacious. As noted earlier, the first four phases of intervention were conducted with Connor's summer teacher. The final baseline and intervention phase (labeled follow-up on the graph) were implemented with Connor's regular teacher.

Conditional probabilities are depicted in the bottom panel of Figure 7. Problem behavior occurred in less than $1 \%$ of all intervals scored with attention deprivation. Attention followed problem behavior $31 \%$ of the time accounting for only $20 \%$ of the attention delivered during attention sessions. These results, when combined with data from the attention baseline showing little to no responding during attention deprivation, along with the results of the frequency graph, suggest that problem behavior was not likely maintained by attention in the presence of attention deprivation. In the presence of prompting (demand baseline), 92\% of problem behavior was followed by attention accounting for 53\% of attention delivered. Additionally, $57 \%$ of problem behavior was followed by escape accounting for 25\% of escape deliveries. During both treatments approximately $14 \%$ of problem behavior was followed by attention and approximately 91\% was followed by a physical prompt (as per the intervention). Escape never 
followed problem behavior in any treatment session. These results suggest that Connor's teacher implemented the interventions with good procedural integrity.

Procedural integrity data are in Table 10. Connor's caregiver implemented the intervention with greater than 85\% accuracy. Most errors occurred during initial sessions and typically consisted of delivering attention with the physical prompt.

Jim

Jim exhibited no problem behavior during either demand or tangible sessions. As a result, no interventions were implemented. This was consistent with results obtained during the SDA in which little to no problem behavior was observed. These results suggest that the SDA had greater treatment utility because Jim did not emit problem behavior in his natural environment.

Susie

Treatment results for Susie are depicted in Figure 8. The top panel depicts rates of problem behavior during tangible sessions. During baseline, Susie emitted an average of 2.3 problem behaviors per min. Following baseline, two interventions were implemented during tangible sessions: toy removal and toy removal plus attention extinction. Toy removal alone resulted in a slight increase in responding relative to baseline. During these sessions, attention was delivered, either as negative attention or as a means of redirecting Susie to interact with another activity, following $91 \%$ of problem behavior. In sessions during which toy removal plus attention delivery for appropriate behavior only was in effect, responding was initially variable but gradually decreased to zero resulting in greater than $80 \%$ reduction from baseline. Responding during baseline sessions of the alternating treatments design remained consistent with responding observed during the initial baseline. Results obtained with Suise suggest that intervention based on the results of the SDA was more efficacious than treatments based on the results of the analog functional analysis.

Results from the conditional probabilities are depicted in the bottom panel of Figure 8. Results indicate that attention delivery followed $84 \%$ and $91 \%$ of problem behavior during baseline and the intervention consisting of toy removal, respectively. Additionally, the preferred item was returned to Susie following 35\% of problem behavior during baseline. Only 5\% of problem behavior occurring during the intervention consisting of toy removal plus attention extinction was followed by attention delivery, accounting for $17 \%$ of the attention delivered. The preferred item was never returned to Susie in any treatment sessions. 
Procedural integrity data are in Table 10. Susie's mother implemented the interventions with at least 83\% accuracy. During the initial sessions and on occasion during later sessions, Susie’s mother delivered attention following problem behavior.

General Discussion

It has been suggested that inclusion of idiosyncratic antecedent variables in functional analyses may result in better predictions of variables maintaining problem behavior (Carr et al., 1997; Iwata et al., 1990; Mace et al., 1993). In the current study, the role of caregivers as therapists in the analog functional analysis was examined by comparing caregiver-conducted analyses to experimenter-conducted analyses. Results obtained with these two analyses were compared to results obtained with the SDA. Finally, the treatment utility of all assessments was examined. The following discussion provides possible explanations for the differences between all three assessments as well as the increased treatment efficacy of the SDA. Finally, implications for future research will be provided.

\section{Differential Patterns Between Analogs}

Differential patterns of responding were observed when the analog functional analysis was conducted by caregivers versus experimenters for all four participants, replicating English and Anderson (2004). For two participants (Andrew, Susie) completely different hypotheses of problem behavior were observed dependent upon who conducted the analyses. For Connor, an additional hypothesis was identified when his caregiver conducted the analog sessions. For Jim, caregiver and experimenter analogs suggested one similar hypothesis but two discrepant hypotheses. These results, when combined with those obtained by English and Anderson, strongly suggest that the presence or absence of a caregiver affects the outcome of analog functional analyses.

English and Anderson (2004) suggested several possible reasons for the discrepant results observed between caregiver-conducted and experimenter-conducted analogs. One explanation is that caregivers may have been differentially paired with various consequences in the past. For example, caregivers might serve as discriminative stimuli in some contexts. To illustrate, a child may have learned that engaging in problem behavior when the caregiver is present (versus absent) is likely to result in attention. Results from Andrew and Susie lend support for this hypothesis. During analog sessions, rates of problem behavior were high during the tangible sessions when conducted by each individuals’ caregiver but not when conducted by the 
experimenter. Andrew’s and Susie’s caregiver might be a discriminative stimulus signaling the availability of reinforcement. Interestingly, tangible delivery (the reinforcer in the analog) never followed problem behavior in the SDA; instead attention delivery appeared to maintain problem behavior. This suggests that, in the context of tangible removal, the presence of caregivers signaled differential availability of reinforcement (attention). In the analog functional analysis, the forthcoming consequence was tangible delivery, not attention per se. It is possible that tangible delivery came to function as a reinforcer for both participants through participation in the analog. Alternatively, attention delivery necessarily co-occurs with tangible delivery in the analog, so it is possible that, even in the analog, problem behavior was maintained by attention delivery not access to the preferred item. A second explanation is that caregivers, or in some cases experimenters, may serve as an establishing operation (EO). Simply the presence of the caregiver or the experimenter may make problem behavior more or less likely to occur because the effectiveness of the reinforcer has been altered when that person is present. For example, interaction with a familiar person may be more reinforcing than interaction with a relative stranger. This may have been the case with Connor during attention sessions. Attention delivery may have been more reinforcing when Connor's caregiver was present, resulting in deprivation of caregiver attention establishing caregiver attention as a reinforcer. Attention from experimenters may not have been reinforcing, thus, Connor did not engage in problem behavior when experimenters were present. Although Connor emitted little problem behavior under attention deprivation in the SDA, it is possible that other events occurring during attention deprivation (e.g., access to less preferred items, other students) lessened the reinforcing effectiveness of attention delivered by his caregiver. Further research is needed to identify what role caregivers play, that of an establishing operation or as a discriminative stimulus.

\section{Differential Patterns Between Analogs and SDA}

When results of the analog functional analyses were compared with results obtained from the SDA, differential findings were observed for all participants. This is in contrast to results reported by Anderson and Long (2002), who found that the analog functional analysis and SDA resulted in similar hypotheses for three of four participants. In the present study, both the SDA and the caregiver-conducted analogs with Andrew, Connor, and Susie suggested that problem behavior was evoked by a similar antecedent event (tangible removal for Andrew and Susie, prompts for Connor), however the two assessments suggested different hypotheses about 
reinforcing consequences. Results following treatments based on the results of each assessment yielded support for the treatment utility of the SDA. Specifically, treatments were more efficacious when based on the results of the SDA than either the caregiver-conducted or experimenter-conducted analogs.

Anderson and Long (2002) found that for three of four participants, similar hypotheses of problem behavior were found between the analog functional analysis and the SDA. Further, interventions based on the two assessments resulted in suppression of problem behavior with both participants for whom intervention was attempted. For the fourth participant, discrepant hypotheses were identified by the two assessments. A comprehensive intervention (consisting of antecedent and consequent manipulations) based on the SDA was implemented across the day resulting in significant reductions in problem behavior.

Several possibilities exist as to why less agreement between analogs and the SDA were observed in this study relative to findings reported by Anderson and Long (2002). First, discrepancies may have resulted because caregivers in Anderson \& Long did not function as either discriminative stimuli or establishing operations, as they may have in the current study. That is, the consequent event might be just as reinforcing regardless of who is present (e.g., familiar versus unfamiliar person). This may have occurred in Anderson \& Long because caregivers for three of four participants were teachers, not parents (in the current study, parents were targeted caregivers for all participants except Conner). Perhaps Anderson \& Long would have obtained different results if the analogs had been conducted with parents, who likely had a longer history of responding to problem behavior then did the children's teachers.

Finally, the functioning level of the participants in this study and those in Anderson and Long (2002) differed. The participants in the current study all functioned in the average range of intelligence to the mild to moderate range of mental retardation range whereas (with the exception of the participant with whom discrepant results were observed) the participants in Anderson and Long functioned in the moderate to profound range of mental retardation. Discrepant results were obtained in Anderson and Long with a participant functioning in the borderline to mild range of mental retardation. Perhaps the analog functional analysis is less accurate with individuals who exhibit only mild cognitive delay. English and Anderson (2004) found similar results when comparing caregiver and experimenter conducted analogs. English and Anderson reported discrepant hypotheses with two individuals functioning in the mild range 
of mental retardation whereas similar hypotheses were derived from the two assessments with the two participants functioning in the moderate to severe mental retardation range.

\section{Treatment Utility of the Analog and the SDA}

The results of this study suggest that including caregivers in an analog functional analysis may result in different patterns of problem behavior, but may not reliably increase intervention efficacy. However, the caregiver-conducted analog was more accurate than the experimenter analog for Andrew and Susie in that the caregiver analog and the SDA identified the same antecedent event, tangible deprivation, which evoked problem behavior. Thus, a treatment based on the caregiver analog is more likely to have been effective than treatments based on the experimenter analog which did not identify an accurate antecedent or consequent event (for Andrew and Susie). Although caregiver-conducted analogs resulted in similar hypotheses to the SDA for two participants, the SDA may be a better choice for pre-treatment functional assessments because caregivers do not need to be trained and participants do not need to be removed from their natural environment. Further, the results obtained from the SDA in the current study and in Anderson \& Long (2002) resulted in more effective treatments for all participants suggesting that when developing efficacious interventions is the goal, the SDA may be a better choice for pre-treatment functional assessment.

The results of this study and of Anderson and Long (2002) suggest that one critical element of the SDA is that consequences were free to vary, allowing for the occurrence of idiosyncratic consequences and schedules of reinforcement. For example, for Andrew and Susie, the naturally occurring consequence when preferred items were removed was attention delivery, not simply access to the preferred item (this is not to suggest that access to the item would not have reinforced problem behavior, as it likely would have, but simply that access to tangibles likely did not maintain problem behavior in the natural environment). For Connor, problem behavior evoked by prompts was maintained by attention delivery (as suggested by the SDA) rather than escape, the programmed consequence for problem behavior during the demand condition of the analog functional analysis. The occurrence of naturally occurring patterns of reinforcement during the SDA likely contributes to the effectiveness of the SDA in identifying the maintaining variable for problem behavior and subsequently in developing an effective intervention. 
One limitation to the SDA necessitates further research. Specifically, conditional probabilities increase the complexity of the SDA and may limit its utility to those who understand and are able to calculate them. Anecdotally, it does not seem that simply examining response frequency of problem behavior would result in accurate hypotheses because the consequent event is not necessarily the event typically associated with the antecedent event which makes conditional probabilities necessary for some participants. For example, for Andrew and Susie responding in the presence of tangible deprivation during the SDA was maintained by attention delivery rather than tangible delivery. One possible alternative to conditional probabilities is to evaluate the use of the ABC assessment form described by O'Neill et al. (1997). Specifically, the assessment form could be used to analyze the occurrence of events during the SDA. Interventions based on the results of the assessment form and conditional probabilities could be systematically evaluated to determine if simply using the assessment form results in efficacious interventions. If so, the ease of the SDA is enhanced increasing the number of people who can utilize the SDA.

Future research also should focus on the schedules with which consequent events are delivered. In the SDAs in the current study and in Anderson and Long (2002), as well as in earlier studies using descriptive assessments (e.g., Lerman \& Iwata, 1993), consequent events rarely if ever were delivered on a continuous reinforcement schedule. Most often it is assumed that the event following problem behavior most often is the maintaining consequence, yet it is possible that events that follow problem behavior only intermittently serve as reinforcers. Future research could evaluate this hypothesis by implementing interventions based not only on the consequence occurring most frequently, but also on consequences occurring only intermittently. For example, in Susie's SDA, tangible delivery followed problem behavior 5\% of the time. Moreover, tangible delivery in the presence of problem behavior only accounted for $26 \%$ of tangible deliveries that occurred. Thus, tangible delivery was more likely to occur in the absence of problem behavior. Consequently, it was assumed that tangible delivery was not maintaining problem behavior because it rarely followed problem behavior and was more likely to occur in the absence of problem behavior.

The results of this study suggest hypotheses derived from the SDA result in more efficacious interventions than hypotheses based on the analog functional analysis when conducted by caregivers or experimenters. More specifically, it seems that the evaluation of 
naturally occurring patterns of reinforcement via a structured assessment is critical. Better hypotheses of problem behavior and thus better treatment recommendations seem to result when the SDA is utilized. Further research is needed to replicate and extend these results. Moreover, further research examining the use of conditional probabilities in the SDA would be beneficial. 


\section{References}

Anderson, C. M., English, C. L., \& Hedrick, T. (in press). Use of the structured descriptive assessment with typically developing children. Behavior Modification.

Anderson, C. M., Freeman, K. A., \& Scotti, J. R. (1999). Evaluation of the generalizability (reliability and validity) of analog functional assessment methodology. Behavior Therapy, 30, 31-50.

Anderson, C. M., \& Long, E. (2002). Evaluation of structured functional assessment methodology. Journal of Applied Behavior Analysis, 35, 137-154.

Bijou, S. W., Peterson, R. F., \& Ault, M. H. (1968). A method to integrate descriptive and experimental fields studies at the level of data and empirical concepts. Journal of Applied Behavior Analysis, 1, 175-191.

Carr, E. G., Yarbrough, S. C., \& Langdon, N. A. (1997). Effects of idiosyncratic stimulus variables on functional analysis outcomes. Journal of Applied Behavior Analysis, 30, 673-686.

Cooper, J. O., Heron, T. E., \& Heward, W. L. (1987). Reversal and alternating treatments designs. Applied Behavior Analysis (pp. 163-194), Upper Saddle River, NJ: Merril.

Durand, V. M., \& Crimmins, D. B. (1998). Identifying variables maintaining self-injurious behavior. Journal of Autism and Developmental Disabilities, 18, 99-117.

English, C. L., \& Anderson, C. M. (2004). Effects of familiar therapists on responding in the analog functional analysis. Research in Developmental Disabilities, 25, 39-55.

Fisher, W. W., O'Connor, J. T., Kurtz, P. F., DeLeon, I. G., \& Gotjen, D. L. (2000). The effects of noncontingent delivery of high- and low-preference stimuli on attention-maintained destructive behavior. Journal of Applied Behavior Analysis, 33, 79-83.

Fisher, W. W., Piazza, C. C., Bowman, L. G., Hagopian, L. P., \& Langdon, N. A. (1994). Empirically derived consequences: A data-based method for prescribing treatments for problem behavior. Research in Developmental Disabilities, 15, 133-149.

Fisher, W. W., Piazza, C. C., Cataldo, M., Harrell, R., Jefferson, G., \& Conner, R. (1993). Functional communication training with and without extinction and punishment. Journal of Applied Behavior Analysis, 26, 23-36.

Hagopian, L., P., Fisher, W. W., Sullivan, M. T., Acquisto, J., \& LeBlanc, L. A. (1998). Effectiveness of functional communication training with and without extinction and 
punishment: A summary of 21 inpatient cases. Journal of Applied Behavior Analysis, 31, 211-235.

Horner, R. H., Day, H. M., \& Day, J. R. (1997). Using neutralizing routines to reduce problem behavior. Journal of Applied Behavior Analysis, 30, 601-614.

Iwata, B. A., Dorsey, M., Slifer, K., Bauman, K., \& Richman, G. (1994). Toward a functional analysis of self-injury. Journal of Applied Behavior Analysis, 27, 197-209. (Reprinted from Analysis and Intervention in Developmental Disabilities, 2, 3-20, 1982)

Iwata, B. A., Pace, G. M., Dorsey, M. F., Zarcone, J. R., Vollmer, T. R., Smith, R. G., et al. (1994). The functions of self-injurious behavior: An experimental-epidemiological analysis. Journal of Applied Behavior Analysis, 27, 215-240.

Iwata, B. A., Vollmer, T. R., \& Zarcone, J. R. (1990). The experimental (functional) analysis of behavior disorders: Methodology, applications, and limitations. In A. C. Repp \& N. N. Singh (Eds.), Perspectives on the use of nonaversive and aversive interventions for persons with developmental disabilities (pp. 301-330). Sycamore, IL: Sycamore.

Iwata, B. A., Vollmer, T. R., Zarcone, J. R, \& Rodgers, T. A. (1993). Treatment classification and selection based on behavioral function. In R. Van Houten \& S. Axelrod (Eds.), Behavior analysis and treatment (pp. 102-125), New York: Plenum.

Lerman, D. C., \& Iwata, B. A. (1993). Descriptive and experimental analysis of variables maintaining self-injurious behavior. Journal of Applied Behavior Analysis, 26, 293-319.

Mace, F. C., \& Lalli, J. S. (1991). Linking descriptive and experimental analyses in the treatment of bizarre speech. Journal of Applied Behavior Analysis, 24, 553-562.

Mace, F. C., Lalli, J. S., Pinter Lalli, E., \& Shea, M. C. (1993). Functional analysis and treatment of aberrant behavior. In R. Van Houten \& S. Axelrod (Eds.), Behavior analysis and treatment (pp. 102-125). New York: Plenum.

O’Neill, R. E., Horner, R. H., Albin, R. W., Storey, K., \& Sprague, J. R. (1989). The functional analysis interview. In R. H. Horner, J. L. Anderson, E. G. Carr, G. Dunlap, R. L. Koegel, \& W. Sailor (Eds.), Functional analysis: A practical assessment guide (pp. 10-23). Eugene: University of Oregon Press.

Pelios, L., Morren, J., Tesch, D., \& Axelrod, S. (1999). The impact of functional analysis methodology on treatment choice for self-injurious and aggressive behavior. Journal of 
Applied Behavior Analysis, 32, 185-195.

Ringdahl, J. E., \& Sellers, J. A. (2000). The effects of different adults as therapists during functional analyses. Journal of Applied Behavior Analysis, 33, 247-250.

Sasso, G. M., Reimers, T. M., Cooper, L. J., Wacker, D., Berg, W., Steege, M., et al. (1992). Use of descriptive and experimental analyses to identify the functional properties of aberrant behavior in school settings. Journal of Applied Behavior Analysis, 25, 809-821.

Shirley, M. J., Iwata, B. A., Kahng, S., Mazaleski, J. L., \& Lerman, D. C. (1997). Does functional communication training compete with ongoing contingencies of reinforcement? An analysis during response acquisition and maintenance. Journal of Applied Behavior Analysis, 30, 93-104.

Shores, R. E., Wehby, J. H., \& Jack, S. L. (1999). Analyzing behavior disorders in classrooms. In A. C. Repp \& R. H. Horner (Eds.), Functional analysis of problem behavior: From effective assessment to effective support (pp. 219-237). New York: Wadsworth Publishing Company.

Touchette, P. E., MacDonald, R. F., \& Langer, S. N. (1985). A daily behavior log for identifying a stimulus control of problem behavior. Journal of Applied Behavior Analysis, 18, 343351.

Wacker, D. P, Steege, M. W., Northup, J., Sasso, G., Berg, W., Reimers, T., Cooper, L., Cigrand, K., \& Donn, L. (1990). A component analysis of functional communication training across three topographies of severe behavior problems. Journal of Applied Behavior Analysis, 23, 417-429. 


\section{Appendix A}

\section{Analog Functional Analysis}

The analog is used to determine why a person may be engaging in problem behavior (e.g., self-injury, aggression, destruction). In the analog, a series of role-plays are used to figure out what events seem to trigger problem behavior, as well what a child seems to get out of the behavior. For example, some children often exhibit problem behavior when a parent is busy (e.g., on the phone, cooking dinner). In this situation, the parent's attention directed elsewhere is a trigger for problem behavior. Often, the child gets attention for engaging in these behaviors, even if it seems like negative attention. A parent might get off the phone and tell the child to be quiet or might have to repeatedly guide the child out of the kitchen. The purpose of the analog functional analysis is to systematically test different triggers and consequences to determine specific reasons why your child misbehaves. Role-plays in the analog are conducted for 10minute sessions. Within a session, specific events are in place. There are four different roleplays: attention, demand, tangible, and toy play.

The purpose of the attention condition is to see if attention deprivation is a trigger for problem behavior and if attention delivery maintains problem behavior. In the attention condition, you and your child will be in the room. There will be toys present for your child to play with. While your child is playing you will be reading a magazine. You should not attend to your child in any way including eye contact, verbal or physical interactions unless your child engages in a problem behavior as defined by the experimenter and yourself. Only then should you deliver attention to your child. The attention should be a brief statement such as “Don’t do that" or "You are going to hurt yourself." For each occurrence of a problem behavior you should deliver a statement. You should not attend to your child if he/she asks you a question, makes a statement, or touches you in a manner not defined as a problem behavior. We know that this seems odd, and different than what you typically do, but the purpose is to see how your child acts in situations during which you really cannot attend to him or her unless you have to (i.e., he or she exhibits problem behavior)

The purpose of the demand condition is to see if presentation of requests triggers problem behavior. Also, we want to see if problem behavior occurs to get out of doing something. In the demand condition, you and your child again will be in the room together. There will be a table and chairs present at which you will sit and work. You will give your child tasks to perform that 
he or she can already do. Some tasks will be things your child willingly completes, and others will be tasks your child does not often do. Examples of tasks include touching his/her nose, picking up the toys, or sitting down. If your child does not comply with your first request, you will again tell him/her what to do and model the behavior yourself. If he/she still does not do the task, you physically prompt him/her to do the task. If at anytime during the task, your child engages in a problem behavior, you will remove the task from the table and turn away from your child for 20 sec. At the end of the 20-sec interval, you will again give your child tasks to do. If your child engages in a problem behavior during the 20-sec interval you will continue to ignore him/her. Again, you are not to answer any questions or statements your child may ask during the session.

The tangible condition is designed to determine if your child is engaging in problem behavior because to gain access to preferred activities or items. In the tangible condition you and your child will be in the room together along with preferred toys or food. Your child will be allowed to play with the toys or consume the food for approximately 2-min prior to the start of the session. At the end of the 2-min you will remove all toys/food from your child. You are to hold the items until your child engages in a problem behavior. Only then are you to place the toys/food on the floor. Your child will have access to the items for $20 \mathrm{sec}$. At the end of the 20sec, you are to remove all toys/food from your child. During the session you should not talk to or physically interact with your child.

In the toy play condition you and your child will be in the room together with toys. You will make a verbal statement to your child every 20 sec. Example statements may include "I like how your are playing” or "You are doing a great job today.” Occurrences of problem behavior should be ignored unless they occur in the last 3-5 sec of the 20-sec interval. For example, it has been 17 sec when your child throws a toy at you. You are to continue the 20-sec interval for another 5 sec without a problem behavior. You should then deliver the statement. As in the previous conditions, all statements or questions should be ignored. You should only provide attention to our child when the 20-sec interval has elapsed. The play condition controls for events that occurred during the previous conditions: attention is delivered to your child, no demands are placed on him/her, and he/she has access to toys/food. Because problem behavior does not result in anything specific (e.g., escape, food, attention) and your child already has the items he/she wants or does not want, it is expected that rates of problem behavior would be low. 
During each condition you will be doing things that may not seem appropriate such as delivering attention only when your child hits you. Delivering these events during each condition at specific times is a systematic way to accurately determine why your child may be engaging in these behaviors. It is important that you continue to respond to your child's behavior the way you normally would and not implement anything you learn during this part of the training at home. In the next phase you will be taught how to best respond to your child's behavior in order to decrease occurrences of problem behavior. 


\section{Appendix B}

\section{Structured Descriptive Assessment (SDA)}

The SDA is used to determine why a person may be engaging in problem behavior (e.g., self-injury, aggression, destruction). In the SDA, a series of role-plays are used to figure out what events seem to trigger problem behavior, as well what a child seems to get out of the behavior. For example, some children often exhibit problem behavior when a caregiver is busy (e.g., on the phone, helping another student). In this situation, the caregiver's attention directed elsewhere is a trigger for problem behavior. Often, the child gets attention for engaging in these behaviors, even if it seems like negative attention. A parent might get off the phone and tell the child to be quiet or might have to repeatedly guide the child out of the kitchen. The purpose of the SDA is to test different triggers and learn what consequences caregivers use to determine specific reasons why your child misbehaves. Role-plays in the SDA are conducted for 10-minute sessions. Within a session, specific events are in place. There are four different role-plays: attention, demand, tangible, and toy play.

The purpose of the attention condition is to see if attention deprivation is a trigger for problem behavior. This condition will be conducted during times when you (the caregiver) do not normally interact with your child (e.g., while cooking dinner or working with another child). Prior to conducting attention sessions, you will be asked to interact with your child in a noninstructional manner for at least 2 min. Preferred tangibles (items used in the tangible condition) will not be present during this time. During this role-play we would like to see how your child behaves when you are engaged in another activity and cannot directly attend to your child. If your child engages in problem behavior, please do what you would normally do; respond as if we were not here.” Keep preferred items out of sight of your child and refrain from placing demands on your child in the absence of problem behavior. If you attend to your child for 2 min in the absence of problem behavior, we will ask you to return to what you were doing.

The purpose of the task condition is to see if asking your child to complete tasks triggers problem behavior. This session will be conducted during times when your child normally is expected to complete tasks. In this role-play, we would like to learn how your child responds when asked to complete a task. Please attempt to have your child work on activities he or she normally should be doing and use whatever strategies you normally use to get your child to complete the task. If your child engages in problem behavior, please do what you would 
normally do in this situation. Please keep preferred items out of sight of your child in the absence of problem behavior. If your stop prompting your child for $2 \mathrm{~min}$ in the absence of problem behavior, we will prompt your to continue asking your child to complete an activity.

The tangible condition is designed to see if removal of preferred items or activities triggers problem behavior. This condition will be conducted during times when access to preferred activities or items normally ends. Prior to the start of the condition, your child will have been given access to the preferred item or activity for at least $2 \mathrm{~min}$. In this role-play, we want to learn how your child responds when preferred activities end. When we tell you to begin, please remove the preferred item. You may interact with your child how you wish but refrain from engaging your child in work activities. If your child engages in problem behavior, please do what you would normally do in this situation, and if this is returning the item please do so. If your child has access to the preferred item for $2 \mathrm{~min}$ in the absence of problem behavior, we will prompt you to remove the item from your child.

The play condition is designed to simulate an enriched environment. Preferred items will be available and you are free to interact with your child as you wish. "In this role-play, we want to learn how your child responds when you are not making requests and preferred items and attention are available. Please play with your child as you normally do. If your child engages in problem behavior, please do what you would normally do in this situation. If you do not interact with your child or allow access to preferred items, or if you place demands on your child for 2 consecutive minutes in the absence of problem behavior, we will ask you to attend to your child, give access to the preferred item, or stop asking your child to complete tasks. 


\section{Author Note}

I express appreciation to Cindy Anderson, Ph.D. for her support and advice throughout the study. I would also like to thank members of my dissertation committee (Andy Lattal, Ph.D., Jennifer McFarland, Ph.D., Tracy Morris, Ph.D., and Mike Perone, Ph.D.) for their advice on earlier drafts of this paper. Finally, I would like to thank Traci Berry, Emily Bowers, Justin Boyd, Theresa Hedrick, and Katrina Zelnick for their help in conducting sessions and analyzing data. 
Table 1

Mean Agreement Scores for Child and Adult Responses in the Analog Functional Analysis

\begin{tabular}{|c|c|c|c|c|c|c|c|c|c|c|}
\hline Participant & $\begin{array}{l}\text { Problem } \\
\text { behavior }\end{array}$ & $\begin{array}{l}\text { Verbal } \\
\text { Prompt }\end{array}$ & $\begin{array}{l}\text { Gestural } \\
\text { Prompt }\end{array}$ & $\begin{array}{l}\text { Physical } \\
\text { Prompt }\end{array}$ & Compliance & $\begin{array}{l}\text { Attention } \\
\text { Delivery }\end{array}$ & $\begin{array}{l}\text { Escape } \\
\text { delivery }\end{array}$ & $\begin{array}{l}\text { End of } \\
\text { escape } \\
\text { interval }\end{array}$ & $\begin{array}{l}\text { Tangible } \\
\text { delivery }\end{array}$ & $\begin{array}{l}\text { Tangible } \\
\text { removal }\end{array}$ \\
\hline Andrew & $\begin{array}{l}94 \% \\
\text { (range } \\
80 \%- \\
100 \% \text { ) }\end{array}$ & $\begin{array}{l}94 \% \\
\text { (range } \\
89 \%- \\
100 \% \text { ) }\end{array}$ & $\begin{array}{l}96 \% \\
\text { (range } \\
81 \%- \\
100 \% \text { ) }\end{array}$ & $\begin{array}{l}99 \% \\
\text { (range } \\
93 \%- \\
100 \% \text { ) }\end{array}$ & $\begin{array}{l}94 \% \\
\text { (range } \\
72 \%- \\
100 \% \text { ) }\end{array}$ & $\begin{array}{l}97 \% \\
\text { (range } \\
92 \%- \\
100 \% \text { ) }\end{array}$ & $\begin{array}{l}90 \% \\
\text { (range } \\
83 \%- \\
100 \% \text { ) }\end{array}$ & $\begin{array}{l}97 \% \\
\text { (range } \\
90 \%- \\
100 \% \text { ) }\end{array}$ & $\begin{array}{l}99 \% \\
\text { (range } \\
94 \%- \\
100 \% \text { ) }\end{array}$ & $\begin{array}{l}99 \% \\
\text { (range } \\
96 \%- \\
100 \% \text { ) }\end{array}$ \\
\hline Connor & $\begin{array}{l}94 \% \\
\text { (range } \\
81 \%- \\
100 \% \text { ) }\end{array}$ & $\begin{array}{l}97 \% \\
\text { (range } \\
85 \%- \\
100 \% \text { ) }\end{array}$ & $\begin{array}{l}96 \% \\
\text { (range } \\
93 \%- \\
100 \% \text { ) }\end{array}$ & $\begin{array}{l}99 \% \\
\text { (range } \\
96 \%- \\
100 \% \text { ) }\end{array}$ & $\begin{array}{l}96 \% \\
\text { (range } \\
89 \%- \\
100 \% \text { ) }\end{array}$ & $\begin{array}{l}97 \% \\
\text { (range } \\
83 \%- \\
100 \% \text { ) }\end{array}$ & $\begin{array}{l}95 \% \\
\text { (range } \\
84 \%- \\
100 \% \text { ) }\end{array}$ & $\begin{array}{l}99 \% \\
\text { (range } \\
93 \%- \\
100 \% \text { ) }\end{array}$ & $\begin{array}{l}99 \% \\
\text { (range } \\
97 \%- \\
100 \% \text { ) }\end{array}$ & $\begin{array}{l}\begin{array}{l}98 \% \\
\text { (range }\end{array} \\
93 \%- \\
100 \% \text { ). }\end{array}$ \\
\hline Jim & $\begin{array}{l}98 \% \\
\text { (range } \\
88 \%- \\
100 \% \text { ) }\end{array}$ & $\begin{array}{l}99 \% \\
\text { (range } \\
89 \%- \\
100 \% \text { ) }\end{array}$ & $\begin{array}{l}98 \% \\
\text { (range } \\
92 \%- \\
100 \% \text { ) }\end{array}$ & $\begin{array}{l}99 \% \\
\text { (range } \\
97 \%- \\
100 \% \text { ) }\end{array}$ & $\begin{array}{l}99 \% \\
\text { (range } \\
91 \%- \\
100 \% \text { ) }\end{array}$ & $\begin{array}{l}97 \% \\
\text { (range } \\
83 \%- \\
100 \% \text { ) }\end{array}$ & $\begin{array}{l}99 \% \\
\text { (range } \\
96 \%- \\
100 \% \text { ) }\end{array}$ & $\begin{array}{l}99 \% \\
\text { (range } \\
96 \%- \\
100 \% \text { ) }\end{array}$ & $\begin{array}{l}99 \% \\
\text { (range } \\
93 \%- \\
100 \% \text { ) }\end{array}$ & $\begin{array}{l}99 \% \\
\text { (range } \\
95 \%- \\
100 \% \text { ) }\end{array}$ \\
\hline Susie & $\begin{array}{l}93 \% \\
\text { (range } \\
72 \%- \\
100 \% \text { ) } \\
\end{array}$ & $\begin{array}{l}99 \% \\
\text { (range } \\
91 \%- \\
100 \% \text { ) } \\
\end{array}$ & $\begin{array}{l}98 \% \\
\text { (range } \\
91 \%- \\
100 \% \text { ) } \\
\end{array}$ & $\begin{array}{l}99 \% \\
\text { (range } \\
98 \%- \\
100 \% \text { ) }\end{array}$ & $\begin{array}{l}97 \% \\
\text { (range } \\
93 \%- \\
100 \% \text { ) } \\
\end{array}$ & $\begin{array}{l}95 \% \\
\text { (range } \\
79 \%- \\
100 \% \text { ) }\end{array}$ & $\begin{array}{l}98 \% \\
\text { (range } \\
89 \%- \\
100 \% \text { ) }\end{array}$ & $\begin{array}{l}98 \% \\
\text { (range } \\
92 \%- \\
100 \% \text { ) }\end{array}$ & $\begin{array}{l}95 \% \\
\text { (range } \\
73 \%- \\
100 \% \text { ) }\end{array}$ & $\begin{array}{l}96 \% \\
\text { (range } \\
78 \%- \\
100 \% \text { ) }\end{array}$ \\
\hline
\end{tabular}


Table 2

Mean Agreement Scores for Child and Adult Responses in the SDA

\begin{tabular}{|c|c|c|c|c|c|c|c|c|c|c|}
\hline Participant & $\begin{array}{l}\text { Problem } \\
\text { behavior }\end{array}$ & $\begin{array}{l}\text { Verbal } \\
\text { Prompt }\end{array}$ & $\begin{array}{l}\text { Physical } \\
\text { Prompt }\end{array}$ & $\begin{array}{l}\text { Ongoing } \\
\text { Task }\end{array}$ & Compliance & $\begin{array}{l}\text { Attention } \\
\text { Delivery }\end{array}$ & $\begin{array}{l}\text { Attention } \\
\text { Deprivation }\end{array}$ & $\begin{array}{l}\text { Escape } \\
\text { delivery }\end{array}$ & $\begin{array}{l}\text { Tangible } \\
\text { delivery }\end{array}$ & $\begin{array}{l}\text { Tangible } \\
\text { removal }\end{array}$ \\
\hline Connor & $\begin{array}{l}98 \% \\
\text { (range } \\
85 \%- \\
100 \% \text { ) }\end{array}$ & $\begin{array}{l}94 \% \\
\text { (range } \\
83 \%- \\
100 \% \text { ) }\end{array}$ & $100 \%$ & $100 \%$ & $100 \%$ & $\begin{array}{l}89 \% \\
\text { (range } \\
79 \%- \\
100 \% \text { ) }\end{array}$ & $\begin{array}{l}91 \% \\
\text { (range } \\
79 \%- \\
100 \% \text { ) }\end{array}$ & $100 \%$ & $\begin{array}{l}99 \% \\
\text { (range } \\
99 \%- \\
100 \% \text { ) }\end{array}$ & $100 \%$ \\
\hline Jim & $100 \%$ & $\begin{array}{l}96 \% \\
\text { (range } \\
81 \%- \\
10 \% \text { ) }\end{array}$ & $\begin{array}{l}99 \% \\
\text { (range } \\
98 \%- \\
100 \% \text { ) }\end{array}$ & $\begin{array}{l}99 \% \\
\text { (range } \\
98 \%- \\
100 \% \text { ) }\end{array}$ & $\begin{array}{l}96 \% \\
\text { (range } \\
81 \%- \\
100 \% \text { ) }\end{array}$ & $\begin{array}{l}94 \% \\
\text { (range } \\
78 \%- \\
100 \% \text { ) }\end{array}$ & $\begin{array}{l}96 \% \\
\text { (range } \\
87 \%- \\
99 \% \text { ) }\end{array}$ & $100 \%$ & $100 \%$ & $100 \%$ \\
\hline
\end{tabular}


Table 3

Formulas Used to Calculate Conditional Probabilities for the Analog Functional Analysis

\section{Proportion of correctly delivered prompts by caregivers \\ Proportion of escape intervals as a consequence of target behaviors}

Proportion of attention delivered as a consequence of target behaviors

Proportion of tangibles delivered as a consequence of target behaviors

Proportion of tangibles removed

\author{
Number of correct prompts \\ Total number of prompts delivered
}

$\frac{\text { Number of escape deliveries that followed problem behavior }}{\text { Total number of escape deliveries }}$

Number of escape deliveries that followed problem behavior Number of problem behaviors not occurring during an escape interval or ITI

Number of problem behaviors that preceded attention delivery Total number of attention deliveries

Number of problem behaviors that preceded attention delivery Total number of problem behaviors

Number of problem behaviors that preceded tangible delivery Total number of tangible deliveries

Number of problem behaviors that preceded tangible delivery Number of problem behaviors not occurring during tangible delivery interval

Number of tangible removals following $15-25$ s access

Total number of tangible removals

Number of tangible removals following $15-25$ s access Number of tangible deliveries 
Table 4

Appropriate Responses by the Therapist in the Analog Functional Analysis

\begin{tabular}{|c|c|c|c|}
\hline Condition & Antecedent & Therapist Behavior & Definition \\
\hline Attention & Target behavior & Attention delivery & $\begin{array}{l}\text { Brief statement about behavior (e.g. “Stop hurting } \\
\text { me.”) or physical contact (e.g., block response) } \\
\text { lasting no longer than 3-5 s }\end{array}$ \\
\hline \multirow[t]{4}{*}{ Demand } & Delivered every 20 s & Verbal prompt & Verbal instruction (e.g., “Stand up.”) \\
\hline & Noncompliance to verbal prompt & Gestural prompt & $\begin{array}{l}\text { Verbal instruction paired with modeling (e.g., } \\
\text { "Stack the blocks," as therapist stacks the blocks) }\end{array}$ \\
\hline & Target behavior & Removal of task & $\begin{array}{l}\text { Removal of task lasting } 15-20 \text {-s given only when } \\
\text { child engages in problem behavior }\end{array}$ \\
\hline & Compliance & Attention delivery & $\begin{array}{l}\text { Verbal statements (e.g., “Good job!” or physical } \\
\text { contact (e.g., hugs, tickles) delivered for } \\
\text { independent response and verbally or gesturally } \\
\text { prompted response }\end{array}$ \\
\hline \multirow[t]{2}{*}{ Tangible } & Target behavior & Tangible delivery & Preferred item delivered to child \\
\hline & $20 \mathrm{~s}$ access & Tangible removal & Preferred item removed from child \\
\hline
\end{tabular}


Table 5

Measures of Procedural Integrity for the Analog Functional Analysis

\begin{tabular}{|c|c|c|c|c|c|c|c|c|c|}
\hline \multirow[b]{2}{*}{ Variable } & \multirow[b]{2}{*}{ Formula } & \multicolumn{2}{|c|}{ Andrew } & \multicolumn{2}{|c|}{ Connor } & \multicolumn{2}{|c|}{$\underline{\mathrm{Jim}}$} & \multicolumn{2}{|c|}{$\underline{\text { Susie }}$} \\
\hline & & Caregiver & Experimenter & Caregiver & Experimenter & Caregiver & Experimenter & Caregiver & Experimenter \\
\hline Prompt & & $93 \%$ & $100 \%$ & $91 \%$ & $100 \%$ & $100 \%$ & $100 \%$ & $98 \%$ & $99 \%$ \\
\hline \multirow[t]{2}{*}{$\begin{array}{l}\text { Escape } \\
\text { delivery }\end{array}$} & $\begin{array}{l}\text { Event- } \\
\text { based }\end{array}$ & $100 \%$ & $100 \%$ & $98 \%$ & $100 \%$ & $87 \%$ & $100 \%$ & $94 \%$ & $100 \%$ \\
\hline & $\begin{array}{l}\text { Behavior- } \\
\text { based }\end{array}$ & $89 \%$ & $100 \%$ & $89 \%$ & $99 \%$ & $100 \%$ & $100 \%$ & $100 \%$ & $100 \%$ \\
\hline \multirow{2}{*}{$\begin{array}{l}\text { Attention } \\
\text { delivery }\end{array}$} & $\begin{array}{l}\text { Event- } \\
\text { based }\end{array}$ & $93 \%$ & $100 \%$ & $81 \%$ & $96 \%$ & $100 \%$ & $100 \%$ & $99 \%$ & $100 \%$ \\
\hline & $\begin{array}{l}\text { Behavior- } \\
\text { based }\end{array}$ & $100 \%$ & $100 \%$ & $86 \%$ & $95 \%$ & $83 \%$ & $97 \%$ & $100 \%$ & $100 \%$ \\
\hline \multirow[t]{2}{*}{$\begin{array}{l}\text { Tangible } \\
\text { delivery }\end{array}$} & $\begin{array}{l}\text { Event- } \\
\text { based }\end{array}$ & $98 \%$ & $100 \%$ & $80 \%$ & $99 \%$ & $100 \%$ & $100 \%$ & $96 \%$ & $100 \%$ \\
\hline & $\begin{array}{l}\text { Behavior- } \\
\text { based }\end{array}$ & $100 \%$ & $100 \%$ & $89 \%$ & $100 \%$ & $100 \%$ & $100 \%$ & $100 \%$ & $100 \%$ \\
\hline \multirow[t]{2}{*}{$\begin{array}{l}\text { Tangible } \\
\text { removal }\end{array}$} & $\begin{array}{l}\text { Event- } \\
\text { based }\end{array}$ & $83 \%$ & $99 \%$ & $76 \%$ & $88 \%$ & $83 \%$ & $99 \%$ & $84 \%$ & $91 \%$ \\
\hline & $\begin{array}{l}\text { Behavior- } \\
\text { based }\end{array}$ & $83 \%$ & $99 \%$ & $76 \%$ & $88 \%$ & $83 \%$ & $99 \%$ & $84 \%$ & $91 \%$ \\
\hline
\end{tabular}




\section{Table 6}

Formulas Used to Calculate Conditional Probabilities for the SDA

\section{Proportion of escape intervals as a} consequence of target behaviors

Proportion of attention delivered as a consequence of target behaviors

Proportion of tangibles delivered as a consequence of target behaviors
Number of intervals with escape deliveries that followed problem behavior Total number of intervals with escape deliveries

Number of intervals with escape deliveries that followed problem behavior Number of intervals with problem behaviors

Number of intervals with problem behaviors that preceded attention delivery Total number of intervals with attention deliveries

Number of intervals with problem behaviors that preceded attention delivery Total number of intervals with problem behaviors

Number of intervals with problem behaviors that preceded tangible delivery Total number of intervals with tangible deliveries

Number of intervals with problem behaviors that preceded tangible delivery Total number of intervals with problem behaviors 
Table 7

Environmental Events Hypothesized by each Functional Assessment to Evoke and Maintain Problem Behavior

\begin{tabular}{|c|c|c|c|c|}
\hline Participant & Event & Experimenter Analog & Caregiver Analog & SDA \\
\hline \multirow[t]{2}{*}{ Andrew } & Antecedent event & Prompt & $\begin{array}{l}\text { Prompt } \\
\text { Tangible deprivation }\end{array}$ & Tangible deprivation \\
\hline & Consequent event & Escape & $\begin{array}{l}\text { Escape } \\
\text { Tangible delivery }\end{array}$ & Attention delivery \\
\hline \multirow[t]{2}{*}{ Connor } & Antecedent event & $\begin{array}{l}\text { Prompt } \\
\text { Tangible deprivation }\end{array}$ & $\begin{array}{l}\text { Attention deprivation } \\
\text { Prompt } \\
\text { Tangible deprivation }\end{array}$ & Prompt \\
\hline & Consequent event & $\begin{array}{l}\text { Escape } \\
\text { Tangible delivery }\end{array}$ & $\begin{array}{l}\text { Attention delivery } \\
\text { Escape } \\
\text { Tangible delivery }\end{array}$ & Attention delivery \\
\hline \multirow[t]{2}{*}{$\mathrm{Jim}$} & Antecedent event & $\begin{array}{l}\text { Prompt } \\
\text { Tangible deprivation }\end{array}$ & Tangible deprivation & None \\
\hline & Consequent event & $\begin{array}{l}\text { Escape } \\
\text { Tangible delivery }\end{array}$ & Tangible delivery & None \\
\hline \multirow[t]{2}{*}{ Susie } & Antecedent event & None & Tangible deprivation & Tangible deprivation \\
\hline & Consequent event & None & Tangible delivery & Attention delivery \\
\hline
\end{tabular}


Table 8

Mean Percentage of Intervals Containing Antecedent Events in the Experimenter Analog and the SDA

\begin{tabular}{|c|c|c|c|c|c|c|c|c|c|}
\hline \multirow[b]{2}{*}{ Condition } & \multirow[b]{2}{*}{ Antecedent } & \multicolumn{2}{|c|}{ Andrew } & \multicolumn{2}{|c|}{ Connor } & \multicolumn{2}{|c|}{ Jim } & \multicolumn{2}{|c|}{ Susie } \\
\hline & & Analog & SDA & Analog & SDA & Analog & SDA & Analog & SDA \\
\hline \multirow[t]{3}{*}{ Attention } & Attention deprivation & 98 & 80 & 95 & 93 & 96 & 94 & 100 & 76 \\
\hline & Prompt & 0 & $<1$ & 0 & 3 & 0 & 0 & 0 & 2 \\
\hline & Tangible denied & & 1 & & 0 & & 0 & & 0 \\
\hline \multirow[t]{3}{*}{ Demand } & Attention deprivation & 47 & 11 & 64 & 19 & 33 & $<1$ & 0 & 10 \\
\hline & Prompt & 40 & 57 & 39 & 41 & 43 & 75 & 64 & 85 \\
\hline & Tangible denied & & 3 & & 7 & & 0 & & 30 \\
\hline \multirow[t]{3}{*}{ Tangible } & Attention deprivation & 100 & 19 & 100 & & 100 & 69 & 100 & 12 \\
\hline & Prompt & 0 & 12 & 0 & & 0 & 2 & 0 & 0 \\
\hline & Tangible denied & & 9 & & & & 17 & & 66 \\
\hline \multirow[t]{3}{*}{ Toy Play } & Attention deprivation & 62 & 11 & 64 & 50 & 60 & 28 & 59 & 39 \\
\hline & Prompt & 0 & 8 & 0 & $<1$ & 0 & 6 & 0 & 6 \\
\hline & Tangible denied & & 2 & & 0 & & 0 & & 0 \\
\hline
\end{tabular}


Table 9

Mean Agreement Scores for Child and Adult Responses in Treatment

\begin{tabular}{|c|c|c|c|c|c|c|c|c|c|c|}
\hline Participant & $\begin{array}{l}\text { Problem } \\
\text { behavior }\end{array}$ & $\begin{array}{l}\text { Verbal } \\
\text { Prompt }\end{array}$ & $\begin{array}{l}\text { Physical } \\
\text { Prompt }\end{array}$ & $\begin{array}{l}\text { Ongoing } \\
\text { Task }\end{array}$ & Compliance & $\begin{array}{l}\text { Attention } \\
\text { Delivery }\end{array}$ & $\begin{array}{l}\text { Attention } \\
\text { Deprivation }\end{array}$ & $\begin{array}{l}\text { Escape } \\
\text { delivery }\end{array}$ & $\begin{array}{l}\text { Tangible } \\
\text { delivery }\end{array}$ & $\begin{array}{l}\text { Tangible } \\
\text { removal }\end{array}$ \\
\hline Andrew & $\begin{array}{l}\begin{array}{l}99 \% \\
\text { (range }\end{array} \\
98 \%- \\
100 \% \text { ) }\end{array}$ & $\begin{array}{l}\begin{array}{l}95 \% \\
\text { (range } \\
83 \%- \\
100 \%\end{array}\end{array}$ & 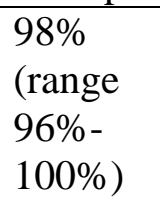 & $100 \%$ & $\begin{array}{l}98 \% \\
\text { (range } \\
94 \%- \\
100 \% \text { ) }\end{array}$ & $\begin{array}{l}93 \% \\
\text { (range } \\
85 \%- \\
100 \% \text { ) }\end{array}$ & 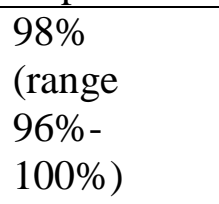 & $\begin{array}{l}\begin{array}{l}98 \% \\
\text { (range }\end{array} \\
93 \%- \\
100 \%\end{array}$ & $100 \%$ & $\begin{array}{l}\begin{array}{l}97 \% \\
\text { (range }\end{array} \\
95 \%- \\
100 \% \text { ) }\end{array}$ \\
\hline Connor & $\begin{array}{l}99 \% \\
\text { (range } \\
92 \%- \\
100 \text { ) }\end{array}$ & $\begin{array}{l}91 \% \\
\text { (range } \\
78 \%- \\
100 \% \text { ) }\end{array}$ & $\begin{array}{l}99 \% \\
\text { (range } \\
93 \%- \\
100 \% \text { ) }\end{array}$ & $\begin{array}{l}97 \% \\
\text { (range } \\
90 \%- \\
100 \% \text { ) }\end{array}$ & $\begin{array}{l}94 \% \\
\text { (range } \\
86 \%- \\
100 \% \text { ) }\end{array}$ & $\begin{array}{l}90 \% \\
\text { (range } \\
81 \%- \\
100 \% \text { ) }\end{array}$ & $\begin{array}{l}99 \% \\
\text { (range } \\
95 \%- \\
100 \% \text { ) }\end{array}$ & $\begin{array}{l}97 \% \\
\text { (range } \\
93 \%- \\
100 \% \text { ) }\end{array}$ & $100 \%$ & $100 \%$ \\
\hline Jim & $100 \%$ & $\begin{array}{l}99 \% \\
\text { (range } \\
96 \%- \\
100 \% 0\end{array}$ & $100 \%$ & $100 \%$ & $\begin{array}{l}97 \% \\
\text { (range } \\
93 \%- \\
100 \% \text { ) }\end{array}$ & $\begin{array}{l}95 \% \\
\text { (range } \\
91 \%- \\
100 \% \text { ) }\end{array}$ & $\begin{array}{l}98 \% \\
\text { (range } \\
97 \%- \\
100 \% \text { ) }\end{array}$ & $100 \%$ & $100 \%$ & $100 \%$ \\
\hline Susie & $\begin{array}{l}99 \% \\
\text { (range } \\
98 \%- \\
100 \% \text { ) }\end{array}$ & $\begin{array}{l}99 \% \\
\text { (range } \\
95 \%- \\
100 \% \text { ) }\end{array}$ & $100 \%$ & $100 \%$ & $100 \%$ & $\begin{array}{l}96 \% \\
\text { (range } \\
91 \%- \\
100 \% \text { ) }\end{array}$ & $\begin{array}{l}98 \% \\
\text { (range } \\
92 \%- \\
100 \% \text { ) }\end{array}$ & $100 \%$ & $100 \%$ & $\begin{array}{l}97 \% \\
\text { (range } \\
95 \%- \\
100 \% \text { ) }\end{array}$ \\
\hline
\end{tabular}


Table 10

Measures of Procedural Integrity in Treatment

\begin{tabular}{|c|c|c|c|c|c|c|c|}
\hline \multirow[b]{2}{*}{ Variable } & \multirow[b]{2}{*}{ Formula } & \multicolumn{2}{|c|}{ Andrew } & \multicolumn{2}{|c|}{ Connor } & \multicolumn{2}{|c|}{ Susie } \\
\hline & & $\begin{array}{l}\text { Toy } \\
\text { removed }\end{array}$ & $\begin{array}{l}\text { Toy removed } \\
\text { plus attention } \\
\text { extinction }\end{array}$ & $\begin{array}{l}\text { Attention during } \\
\text { the break }\end{array}$ & $\begin{array}{l}\text { No attention } \\
\text { during the } \\
\text { break }\end{array}$ & $\begin{array}{l}\text { Toy } \\
\text { removed }\end{array}$ & $\begin{array}{l}\text { Toy removed } \\
\text { plus attention } \\
\text { extinction }\end{array}$ \\
\hline \multirow{2}{*}{$\begin{array}{l}\text { Escape } \\
\text { delivery }\end{array}$} & Event-based & & & $100 \%$ & $100 \%$ & & \\
\hline & $\begin{array}{l}\text { Behavior- } \\
\text { based }\end{array}$ & & & $100 \%$ & $100 \%$ & & \\
\hline \multirow{2}{*}{$\begin{array}{l}\text { Physical } \\
\text { Prompt }\end{array}$} & Event-based & & & $100 \%$ & $100 \%$ & & \\
\hline & $\begin{array}{l}\text { Behavior- } \\
\text { based }\end{array}$ & & & $92 \%$ & $91 \%$ & & \\
\hline \multirow{2}{*}{$\begin{array}{l}\text { Attention } \\
\text { delivery }\end{array}$} & Event-based & N/A & $99 \%$ & $97 \%$ & $97 \%$ & N/A & $83 \%$ \\
\hline & $\begin{array}{l}\text { Behavior- } \\
\text { based }\end{array}$ & N/A & $92 \%$ & $86 \%$ & $87 \%$ & N/A & $95 \%$ \\
\hline \multirow{2}{*}{$\begin{array}{l}\text { Tangible } \\
\text { delivery }\end{array}$} & Event-based & $100 \%$ & $100 \%$ & & & $100 \%$ & $100 \%$ \\
\hline & $\begin{array}{l}\text { Behavior- } \\
\text { based }\end{array}$ & $100 \%$ & $100 \%$ & & & $100 \%$ & $100 \%$ \\
\hline
\end{tabular}




\section{Figure Captions}

Figure 1. Rate of problem behavior per minute during all phases of the analog functional analysis for Andrew (top panel); rate of problem behavior per minute in the SDA (middle panel); proportion of problem behavior intervals that occurred in the presence of putative establishing operations that preceded events (bottom left panel); and proportion of event intervals following problem behavior that occurred in the putative establishing operation during assessment conditions (bottom right panel) of the SDA.

Figure 2. Rate of problem behavior per minute during all phases of the analog functional analysis for Connor (top panel); rate of problem behavior per minute in the SDA (middle panel); proportion of problem behavior intervals that occurred in the presence of putative establishing operations that preceded events (bottom left panel); and proportion of event intervals following problem behavior that occurred in the putative establishing operation during assessment conditions (bottom right panel) of the SDA.

Figure 3. Rate of problem behavior per minute during all phases of the analog functional analysis for Jim (top panel); rate of problem behavior per minute in the SDA (middle panel); proportion of problem behavior intervals that occurred in the presence of putative establishing operations that preceded events (bottom left panel); and proportion of event intervals following problem behavior that occurred in the putative establishing operation during assessment conditions (bottom right panel) of the SDA.

Figure 4. Rate of problem behavior per minute during all phases of the analog functional analysis for Susie (top panel); rate of problem behavior per minute in the SDA (middle panel); proportion of problem behavior intervals that occurred in the presence of putative establishing operations that preceded events (bottom left panel); and proportion of event intervals following 
problem behavior that occurred in the putative establishing operation during assessment conditions (bottom right panel) of the SDA.

Figure 5. Rate of problem behavior per minute during demand baseline sessions for Andrew (top panel); rate of problem behavior per minute during tangible baseline and intervention sessions (middle panel); proportion of problem behavior intervals that occurred in the presence of putative establishing operations that preceded events (bottom left panel); and proportion of event intervals following problem behavior that occurred in the putative establishing operation during intervention conditions (bottom right panel).

Figure 6. Rate of problem behavior per minute during attention baseline sessions (top panel) and tangible baseline sessions (bottom panel) for Connor.

Figure 7. Rate of problem behavior per minute during demand baseline and intervention sessions for Connor (top panel); proportion of problem behavior intervals that occurred in the presence of putative establishing operations that preceded events (bottom left panel); and proportion of event intervals following problem behavior that occurred in the putative establishing operation during intervention conditions (bottom right panel).

Figure 8. Rate of problem behavior per minute during tangible baseline and intervention sessions for Susie (top panel); proportion of problem behavior intervals that occurred in the presence of putative establishing operations that preceded events (bottom left panel); and proportion of event intervals following problem behavior that occurred in the putative establishing operation during intervention conditions (bottom right panel). 
Functional Assessment 58
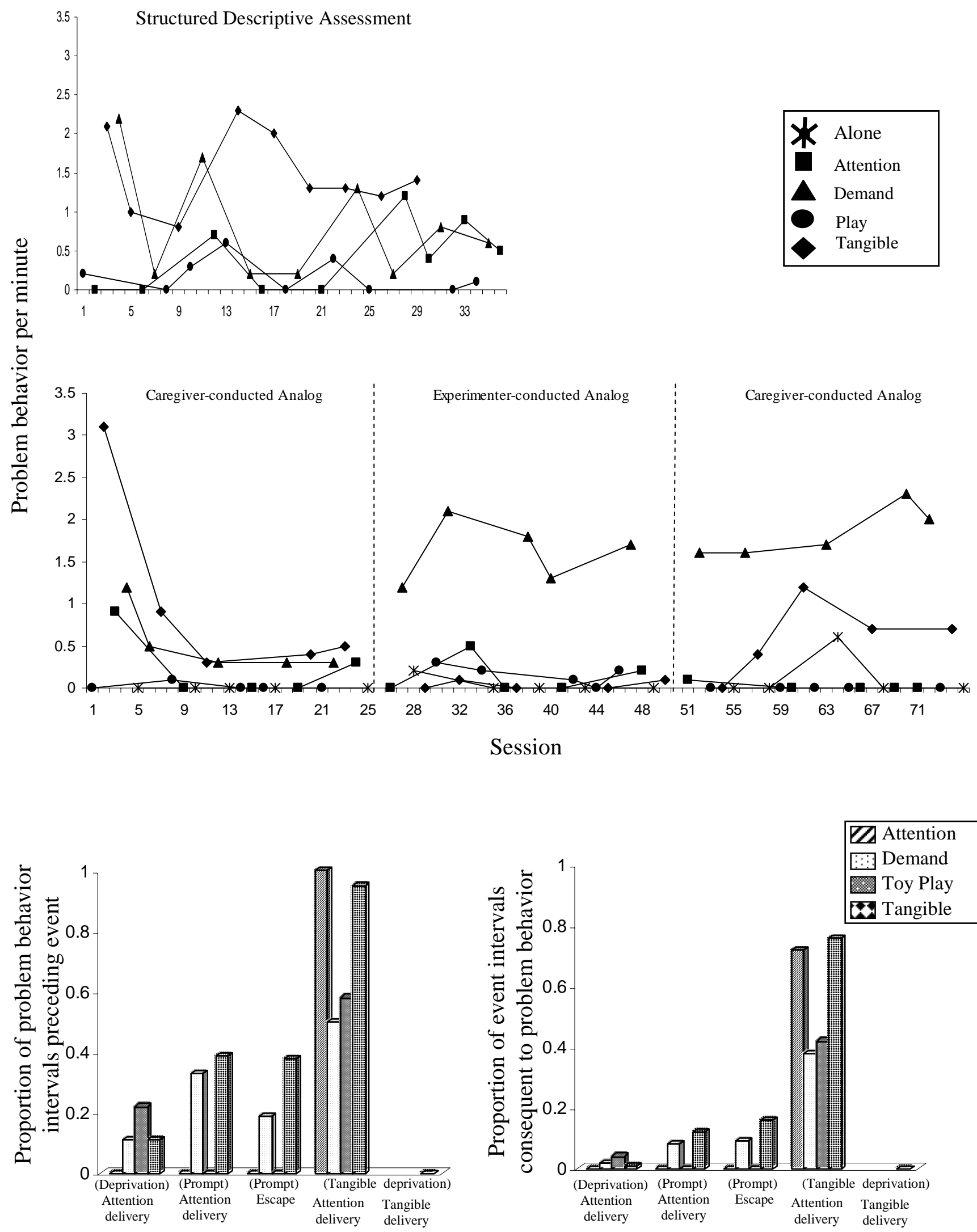

Andrew 


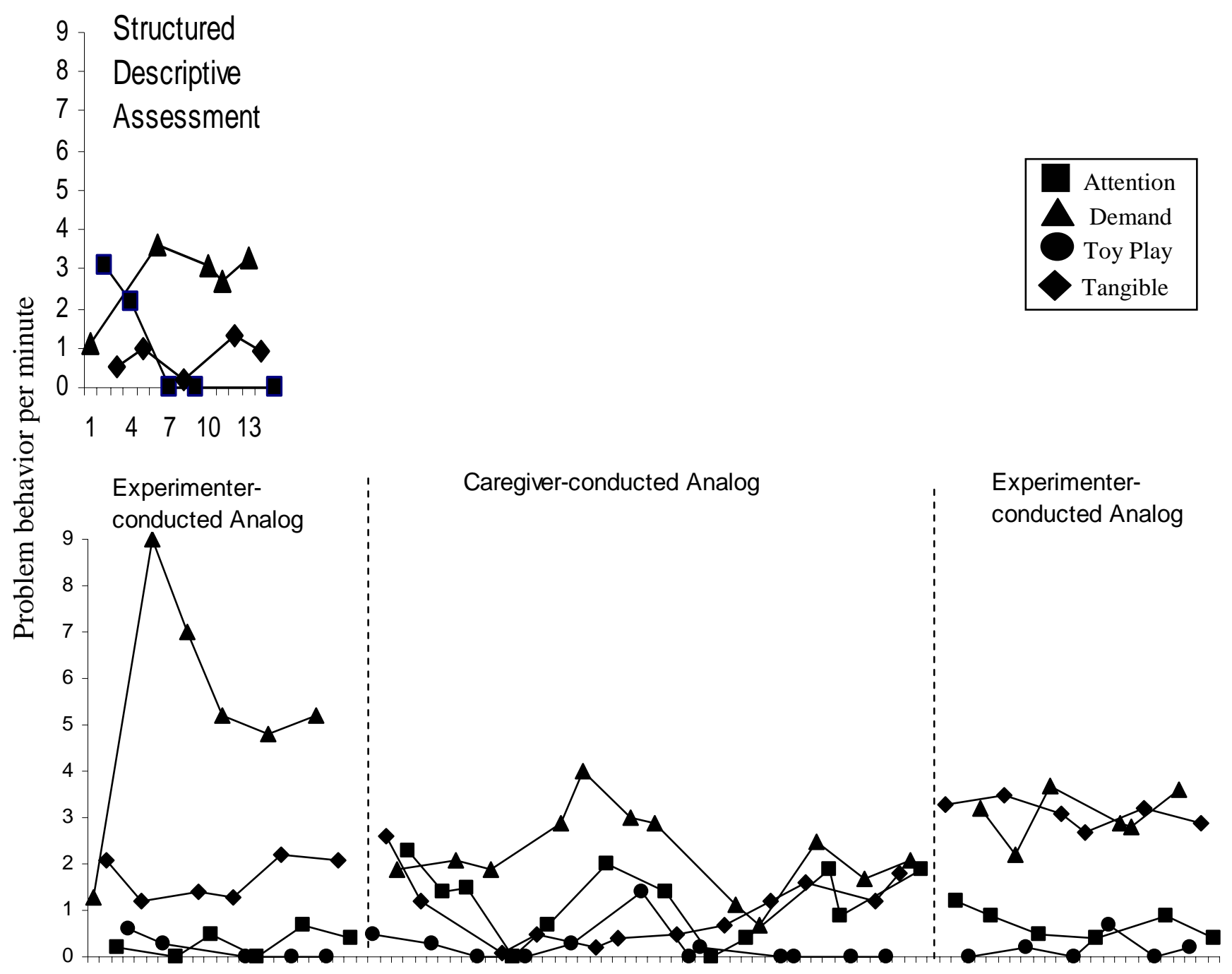

$\begin{array}{lllllllllllllllllllllllllllllllll}1 & 4 & 7 & 10 & 13 & 16 & 19 & 22 & 25 & 28 & 31 & 34 & 37 & 40 & 43 & 46 & 49 & 52 & 55 & 58 & 61 & 64 & 67 & 70 & 73 & 76 & 79 & 82 & 85 & 88 & 91 & 94 & 97\end{array}$ Session
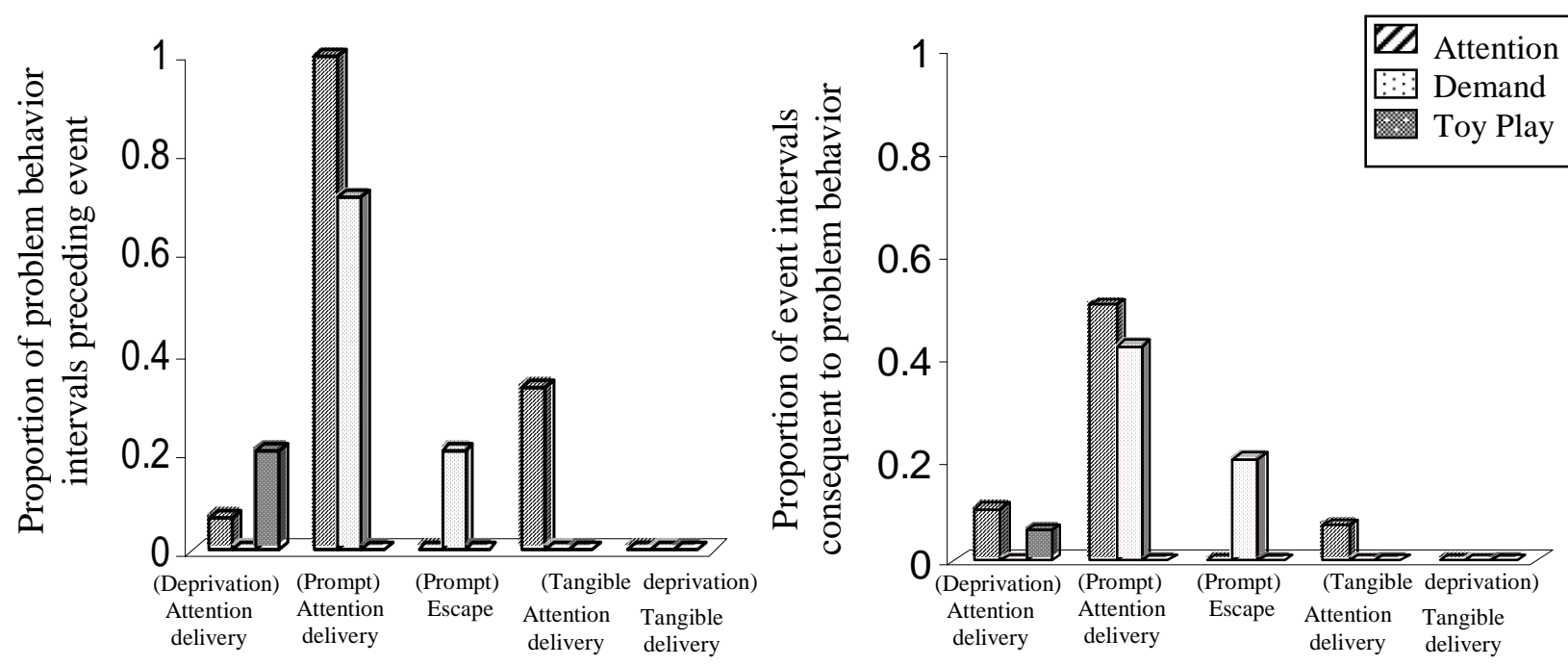

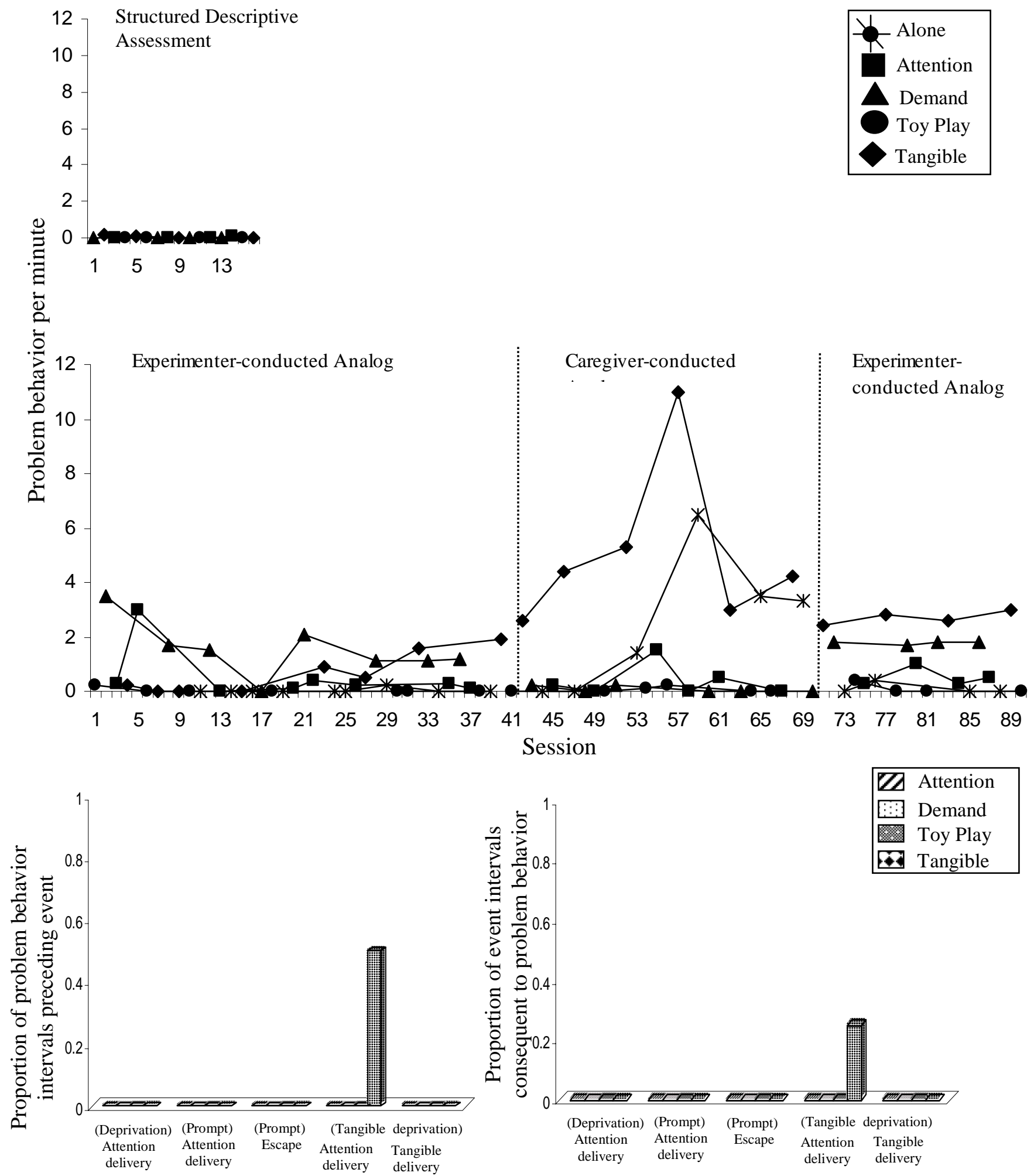
Structured Descriptive Assessment
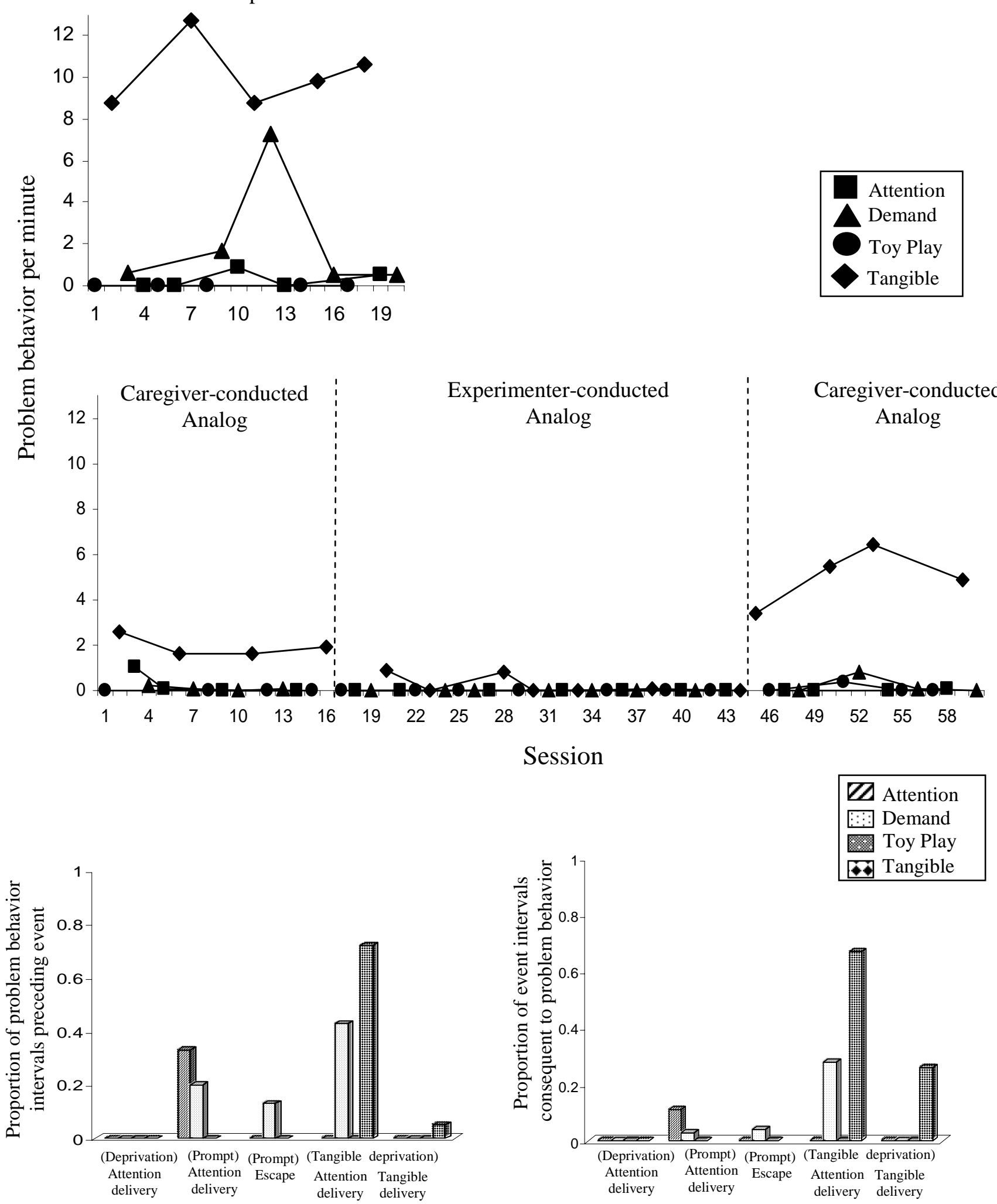

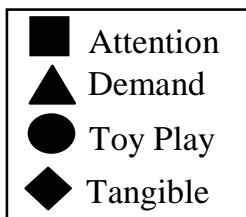

Caregiver-conducted Analog

Z7ttention

Demand

Toy Play

Tangible

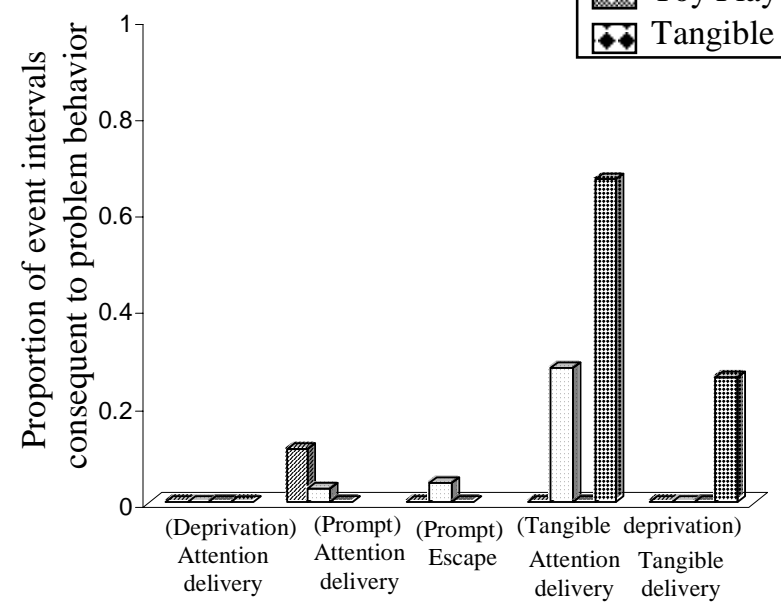



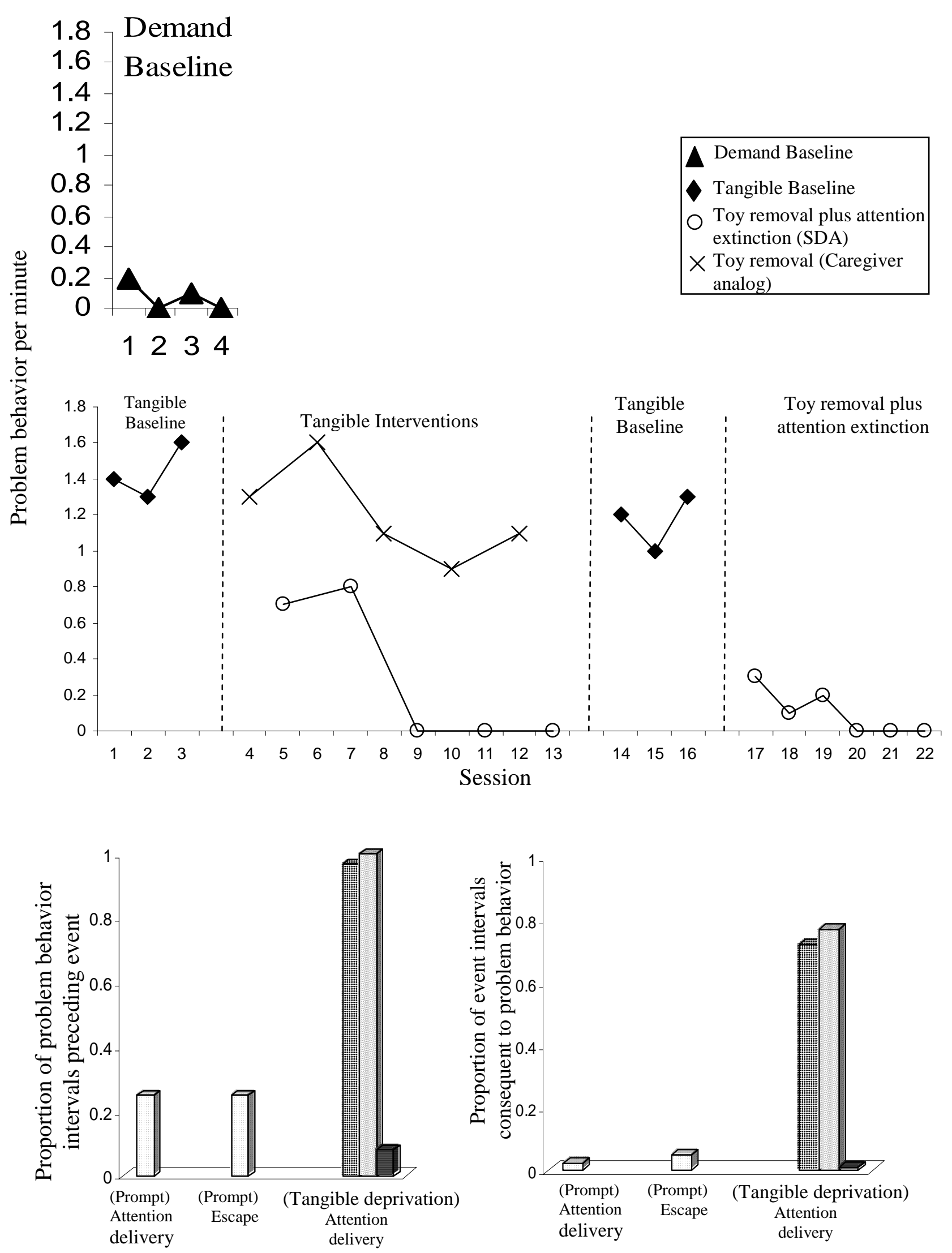

Andrew 
Attention Baseline

(Caregiver Analog)

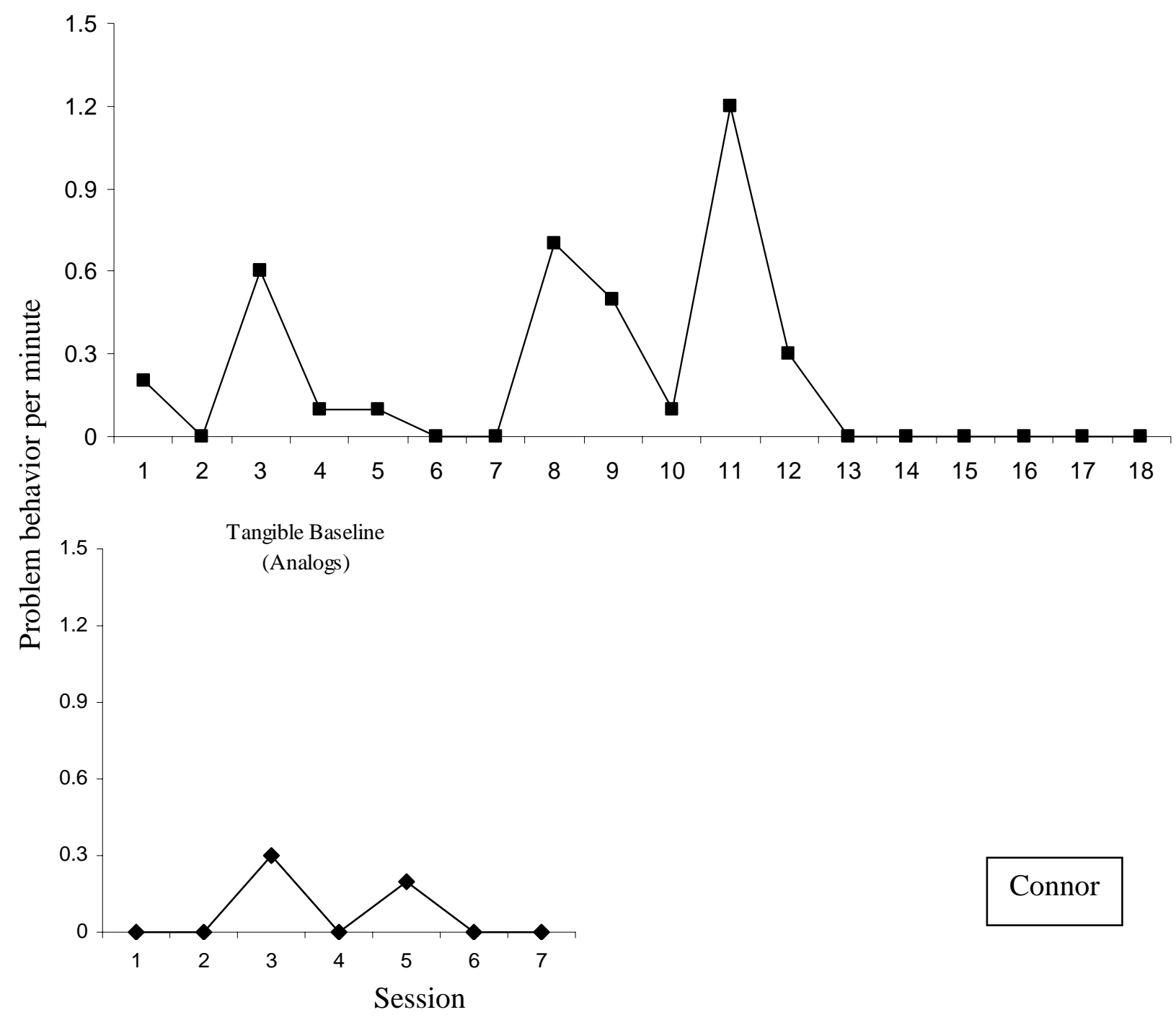



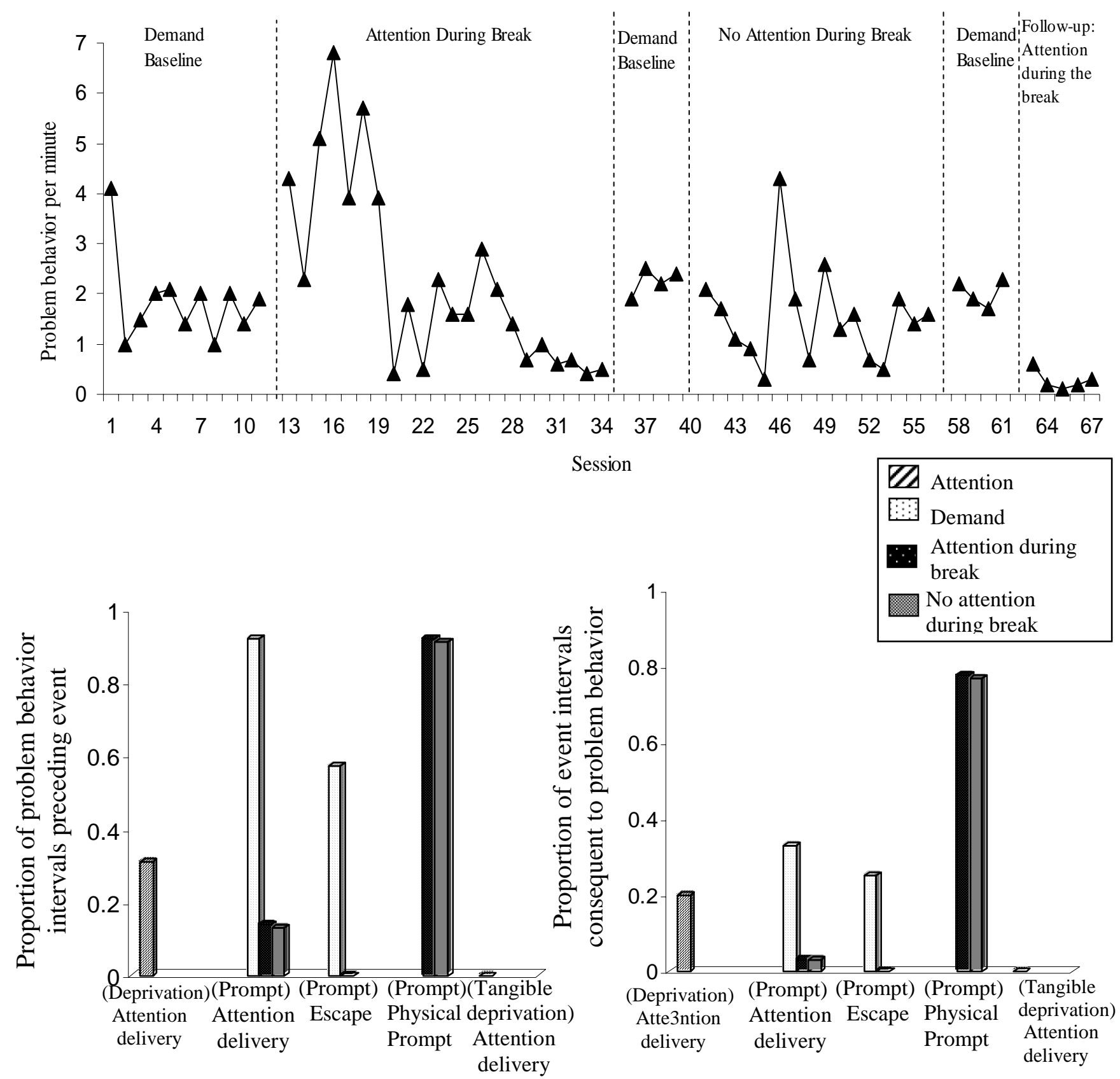

Connor 
Functional Assessment 65

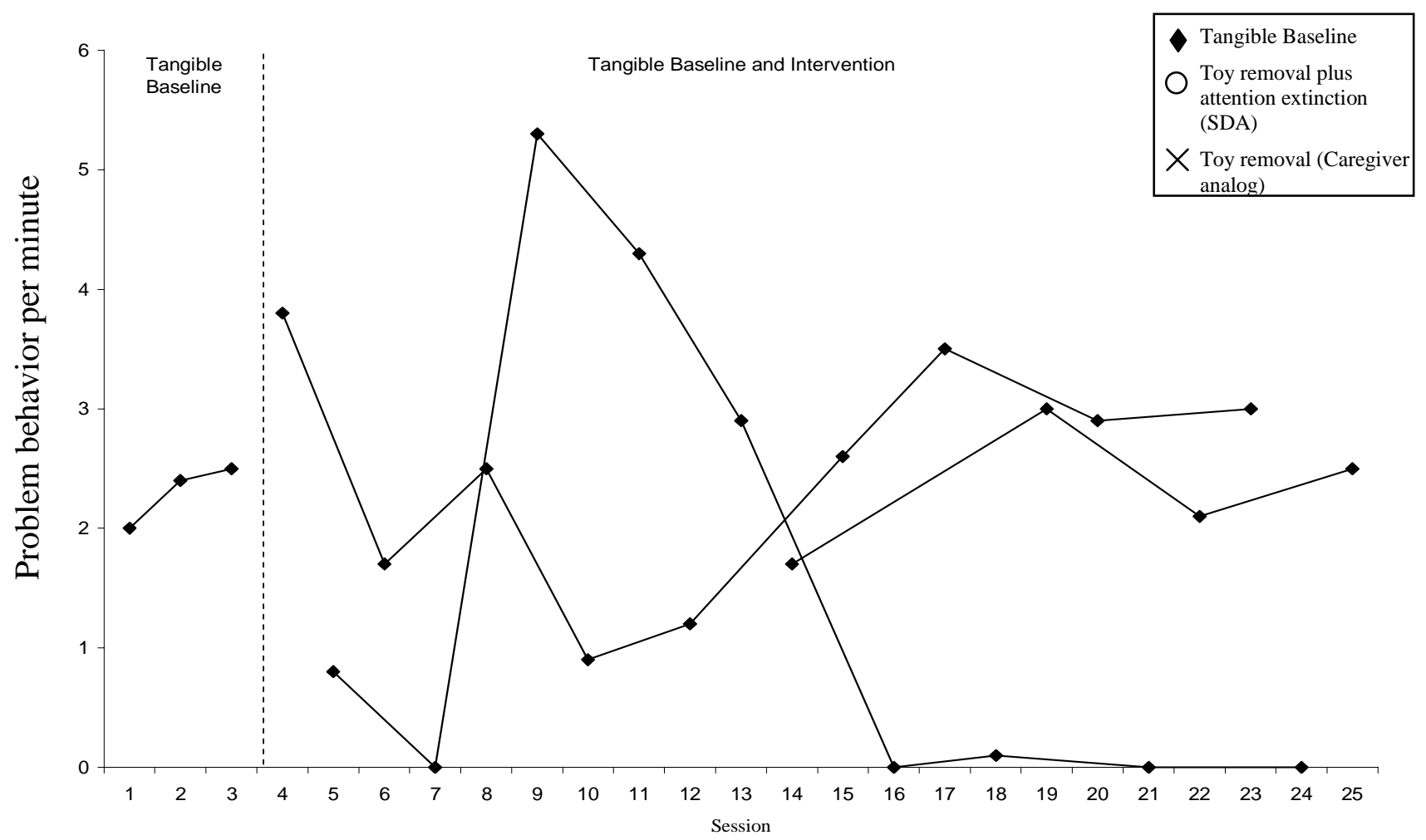

6. Tangible Baseline Toy removal plus 3 attention extinction (SDA)

Toy removal (Caregiver analog)
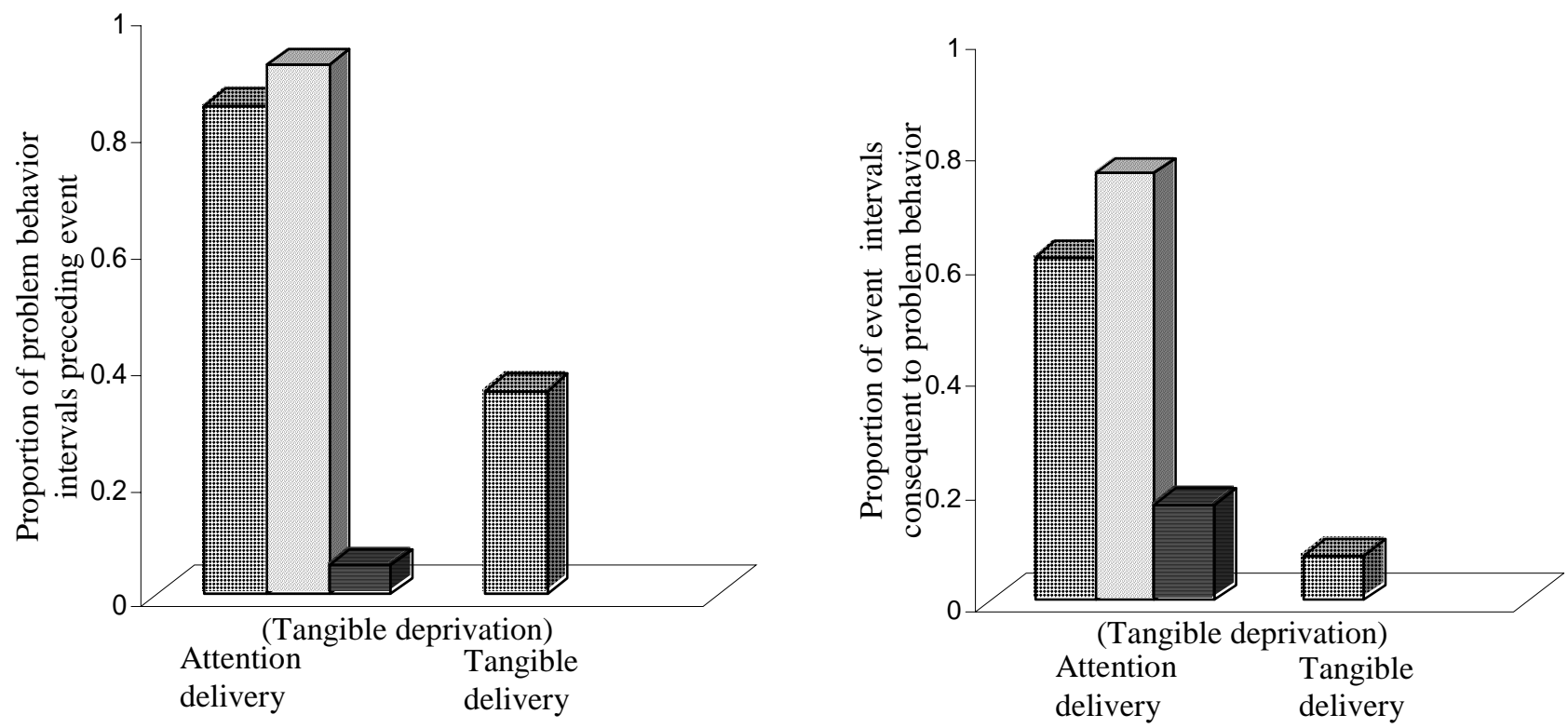

Susie 